Розглянуто проблемні питання моторних експериментів в умовах нестабільного згоряння. Практичним завданням було експериментальне дослідження впливу параметрів іскрового розряду системи запалювання на роботу газового двигуна навколо межі збіднення суміші. Досліджувалась можливість розширення меж збіднення суміші шляхом застосування високоенергетичної іскрової конденсаторної системи запалювання за умови обмеження інтенсивності ерозї поверхні електродів свічок запалювання. Окрема увага надавалася нестабільності іскрового розряду як процеса передачі пориії енергї в суміш з метою створення первинного осередку горіння.

Після аналізу результатів експерименту було виявлено його вагомі недоліки, що пов'язані з відсутністю врахування явища циклової нестабільності процесів до займання суміші - наприклад, іскрового розряду на електродах свічки запалювання. Цей факт змусив грунтовно переглянути метод експериментального дослідження $i$ сформулювати технічні вимоги до вимірювальної апаратури.

Запропоновано новий метод стендових випробувань иляхом застосування новітньої автоматизованої системи поциклового вимірювання параметрів іскрового розряду з одночасною обробкою записуваних індикаторних діаграм і статистичним аналізом результатів за останні 1000 моторних циклів. Головна перевага методу - підвищення достовірності результатів експерименту на газовому двигуні з концепцією бідного згоряння та скорочення часу пошуку помилок експерименту.

Враховуючи, що даний метод може бути реалізований тільки в спечіалізованому програмно-апаратному вимірювальному комплексі, сформовані функціональні вимоги як частина технічного завдання на розробку нового вимірювального комплексу.

Отримані результати можуть бути корисними для підготовки експериментальних досліджень бідного згоряння в газових ДВЗ на етапі планування експеримента і вибору вимірювальної anapamypu

Ключові слова: газовий двигун, циклова нестабільність, осередок горіння, енергія запалювання, іскровий розряд, статистичний аналіз
UDC 621.43.056

DOI: $10.15587 / 1729-4061.2018 .140484$

DEVELOPMENT OF A METHOD FOR

EXPERIMENTAL INVESTIGATION OF COMBUSTION PROCESS IN LEAN BURN GAS ENGINES

\section{Shvydky y}

Engineer

Departament of research and development

Company "Motortech $\mathrm{GmbH} \& \mathrm{Co} . "$

Hogrever str., 21-23, Celle,

Germany, 29223

Postgraduate student Department of internal combustion engines Kharkiv National Automobile and Highway University

Yaroslava Mudroho str., 25, Kharkiv, Ukraine, 61002

E-mail: d.shvidkii@gmx.de

\section{Introduction}

Piston spark-ignition gas engines are used as power units in various fields of operation. Each of the operation fields imposes specific requirements on technical and economic characteristics. Popular applications are industrial gas engines of cogeneration plants, operating on various gas fuels. Technical solutions for industrial piston lean burn gas engines in many respects differ from autotransport gas engines due to the specifics of this application segment:

- stationary power units;

- long service life (up to 90,000 machine hours) when operating round the clock in almost constant or slowly changing speed mode and at full or near full loads;

- rather high efficiency.

However, the use of gas engines in marine transport, powered by liquefied natural gas (LNG) has also become popular in recent years. Power range - from $60 \mathrm{~kW}$ (e. g. MAN E0834 or MAN E3262) to 19 MW (e. g. Wärtsilä 16V46DF or MAN 18V51/60G). The most popular applications of industrial lean burn gas engines:
- cogeneration plants with a capacity from $100 \mathrm{~kW}$ to $2 \mathrm{MW}$ for electric power export to the grid and heat generation, operating as alternative decentralized power sources on alternative types of gas fuel: biogas in livestock and agricultural farms, gas from municipal sewage treatment plants, landfills, coal mining gas, freaking gas (popular in the USA), etc.;

- cogeneration plants with a capacity from $100 \mathrm{~kW}$ to $19 \mathrm{MW}$, operating on natural gas to provide heat and electric power to production facilities, public utilities or greenhouses. For example, flowers in the Dutch greenhouses receive carbon dioxide from the purified exhaust gases of industrial gas engines, as well as heat and light;

- compressed air stations, powered by gas engines;

- pumping stations on gas pipelines or oil pipelines, powered by gas engines;

- generating capacities of offshore drilling platforms or land-based drilling sites for oil and gas production, operating on associated gas;

- power units for electric power generation and/or powering of ferries and LNG tankers.

However, compliance with the regulatory requirements for exhaust gas ecology is obligatory. For example, in Ger- 
many, the requirements to stationary power plants for carbon monoxide (CO) and nitrogen oxide (NOx) emissions depend on the type of gas fuel, plant capacity and chosen combustion concept (stoichiometric combustion or lean burn). Failure to comply with the requirements throughout the operation entails the risk of losing a license of power export to the grid, which is regularly monitored. Fulfillment of the requirements for NOx emissions, whose limit is within $250 \ldots 500 \mathrm{mg} / \mathrm{m}^{3}$ is the most critical. For the reliable implementation of standards, engine operators and manufacturers prefer to have a certain margin for the emission level.

One way to significantly reduce emissions of NOx in exhaust gases and improve efficiency is lean burn [1-3] (Fig. 1). The reason is that with mixture leaning, the combustion temperature in engines decreases exponentially, and NOx formation is proportional to the combustion temperature.

Hard-to-burn gas fuels, such as biogas with the $\mathrm{CO}_{2}$ content of up to $40 \%$, have a fraction of a noncombustible component and further dilute the mixture.

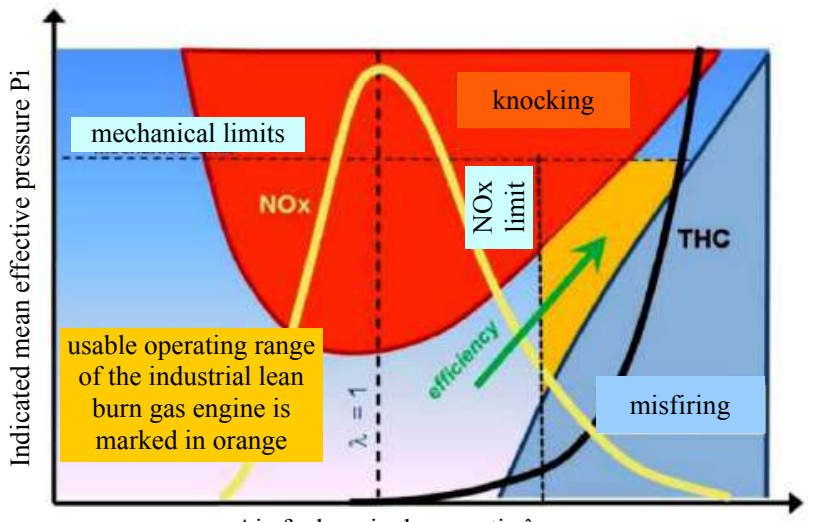

Air-fuel equivalence ratio $\lambda$

Fig. 1. Effect of load conditions and composition of the methane-air mixture on the composition of exhaust gases, probability of detonation and region of possible misfires [3]

Deep mixture leaning and/or dilution with a noncombustible component is accompanied by the known difficulties - an increase in cyclic instability (Fig. 2), increased misfire rate and increased emission of unburned $\mathrm{CxHy}$ hydrocarbons, which imposes restrictions on the maximum applicable value of the air-fuel ratio and operating mode of the gas engine (Fig. 1), reducing its consumer qualities $[2,3]$. For example, for the industrial gas engines, the operation is allowed that satisfies the following conditions:

- compliance with emission standards;

- the coefficient of cyclic instability of the mean indicated pressure no more than $5 \%$ [4];

- the share of misfires no more than $1-3 \%$.

In the field of operation of industrial gas engines, expansion of lean limits and/or applicability of alternative gas fuels without major design changes and under the preservation of the life of the components, for example by using high-power ignition systems (IS), optimizing the fuel equipment or gas exchange processes is of interest.

On the other hand, verification of mathematical models through experimental investigations within scientific works is required. At the same time, the important task is collecting reliable experimental data and statistical processing, which allows identifying degrees of interrelation in order to reveal cause-effect relationships. The latter is greatly complicated in the conditions of poor repeatability of an experiment, for example, under the strong cyclic instability of both the combustion process and initial pre-ignition conditions (mixture formation, charging, ignition). Factors often affect each other, which complicates the process of their identification and exclusion. So, any practical verification of a mathematical model as a theoretical background depends on the success of the experiment, reliability of its results. The correct organization of the experiment using appropriate equipment for collecting and processing experimental data, considering the features of the research object (lean burn gas engine), is necessary. The peculiarities of the research include the possible manifestation of significant cyclic instability (CI) of any of the processes in the investigated operating modes.

\section{Literature review and problem statement}

The search for materials was carried out to explain the results of previous experiments on the engine test bench and to identify possible causes of CI of both the work process and spark discharge. Among a small number of materials on this subject, the papers [2-6] that allow a detailed analysis of a wide range of causes of CI of lean burn in gas engines and determining their cause-effect relationships can be singled out.

The dependence of the law of distribution of spark discharge characteristics, for example breakdown voltage, on the gas medium conditions is considered in detail in the field of high-voltage engineering [7]. The study of discharge phase transitions from glow to arc has been carried out in $[6,8]$. In these papers, the instability factor of the spark discharge in a compressed air medium when conducting a series of discharges under the same initial conditions has been considered. However, no experimental data on the instability of the spark discharge in the gas engine operating conditions have been found, although the experimental methods, according to [6-8], can be used in an experiment on a gas engine to estimate the instability of the spark discharge parameters.

The experimental investigation of heat losses during the transmission of energy from the spark discharge at the spark plug (SP) electrodes to the surrounding compressed air gas medium has been described in [9]. However, no experimental data on heat transfer from the discharge at the SP electrodes to the gas medium under the gas engine operating conditions have been found, although the results of [9] can be used in an experiment on a gas engine.

In [10], the study of the dependence of the probability of the flame kernel formation on the portion of energy transferred to the gas medium by means of the arc discharge has been described. The study has been carried out in a "bomb" vessel filled with a heated hydrogen-air mixture. In [5], the study of the dependence of the probability of the flame kernel formation on the air-fuel ratio and filling pressure of methan-air mixture in a "bomb" vessel after spark discharge has been described. From the works [5, 10] it becomes known that even with the constancy of the initial physical conditions of the mixture before ignition, the cyclic instability of the combustion process is observed, the causes of which were not defined in the works. The results of $[5,10]$ can be used in an experiment on a gas engine for statistical estimation and graphical representation of lean limits. 
However, no works have been found on experimental studies of the cyclic instability of the spark discharge at the spark plug electrodes in a lean burn gas engine and its contribution to:

- instability of time of the flame kernel formation;

- probability of the flame kernel formation.

The cyclic instability of the spark discharge and the subsequent combustion process requires reconsideration and optimization of the experimental research method. In gas engines (i. e., on the engine test bench) operating on a methane-air mixture, no experimental studies have been conducted on the dependence of the flame kernel formation rate and probability on:

- the spark discharge energy in a wide range;

- air-fuel ratio up to the lean limit.

\section{The aim and objectives of the study}

The aim of the study is the formation of functional requirements to the development of a universal measurement system with an automated data acquisition and processing for bench testing of the lean burn gas engine.

To achieve this aim, the following objectives were formulated:

- to analyze the causes of cyclic instability of combustion processes and cyclic instability of pocesses before ignition of mixture (mixture formation, charging, ignition) in lean burn gas engines;

- to analyze the influence of the supply form and amount of energy of the electric discharge at the spark plug electrodes on the process of the flame kernel formation and the level of its CI;

- taking into account the process CI, to develop an optimum method of collection and statistical processing of data of a set of cycles for the current gas engine operating mode on the engine test bench;

- to form functional requirements to the software and hardware parts of measurement system for studying the combustion process in gas engines.

\section{Analysis of the causes of cyclic instability of combustion processes and cyclic instability of pocesses before ignition of mixture}

\section{1. Manifestation of cyclic instability}

The cyclic instability of combustion processes (CICP) is observed as a phenomenon with a certain law of distribution of a random variable (for example, mean indicated pressure per cycle $-\mathrm{Pi}$ ), provided that the engine operating mode is constant.

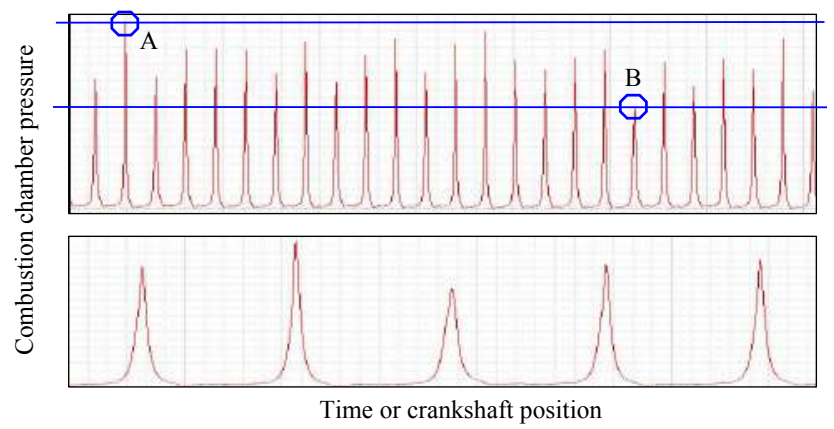

Fig. 2. Increased $\mathrm{Cl}$ of the work process when operating on an ultra-lean mixture - the best $(A)$ and the worst $(B)$ combustion scenario for 25 cycles
The reason for CICP can be the instability of the initial conditions before ignition of mixture. However, the study in [5], through experiments in the "bomb" with the use of spark ignition, makes it possible to best observe the constancy of the initial conditions of the gas medium. Shooting of a series of cycles at each point of the "charging pressure/ mixture composition" field was made (Fig. 3). Before each experiment, the mixture was heated to a temperature of $+110{ }^{\circ} \mathrm{C}$.

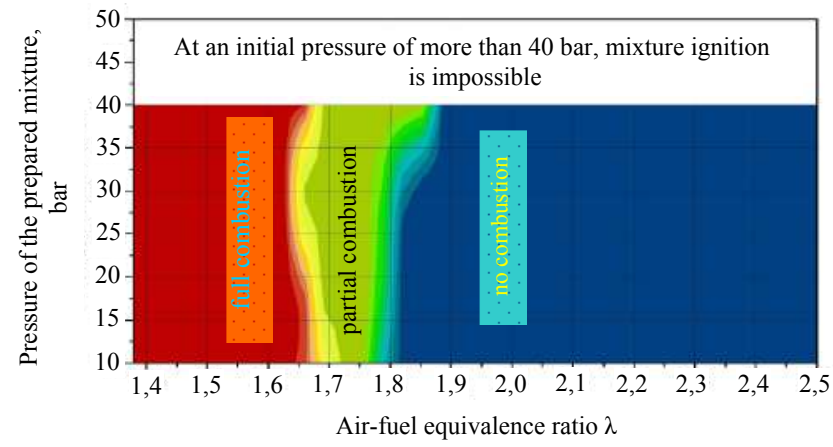

Fig. 3. Experiments in the "bomb", the probability of the flame kernel formation and complete mixture burn-out after the discharge of the inductive IS "MORRIS" [5]

According to the results of combustion in the "bomb" [5], the combustion CI is also manifested and "blurred" boundaries of the flame kernel formation conditions and boundaries of complete combustion conditions are found.

4. 2. Dependence of $\mathbf{C I}$ of the work process on probable options of the combustion process

The engine CICP phenomenon is based on the fact that mixture leaning slows down the process of the flame kernel formation and the process of flame front propagation in the combustion chamber space relative to the duration of mechanical stroke of hear engine [4]. As shown in the example (Fig. 4), let us imagine the process of mixture burnout over time, consisting first of the area of the flame kernel formation and further active heat release. The active heat release corresponds to the flame front propagation and afterburning in the combustion chamber space. Two processes - chemical combustion with heat release and mechanical operation of the heat machine - flow simultaneously. Let us imagine that for a set of engine cycles, for a number of reasons, various options of the process of mixture bur-out over time are observed. We note among them the fastest, the slowest and some medium-long option. Consider the development of work processes (WP) at two different crankshaft speeds. Under the conditions of the same three scenarios of mixture burn-out over time, the level of the WP CI should increase with a smaller ratio of the duration of the combustion process and heat engine cycle. The logical conclusion is that with the inevitable (for a number of reasons) fluctuations of the combustion process from cycle to cycle, some acceleration of the process of the flame kernel formation and acceleration of the process of flame front propagation are necessary. This is necessary to achieve a combustion time, as less as possible than the heat engine strok time. Changing of the ignition time (IT) $\theta$ will adjust the WP options, affect the average parameters of a set of cycles, but will not exclude the manifestation of the CICP and the CIWP as such. 
Mixture leaning and/or dilution with an incombustible component reduce the propagation rate of the laminar flame front and thereby aggravates the situation with the level of cyclic instability of the WP.

It should be noted that in practice, due to the intensification of the charge movement in the combustion chamber with increasing the piston speed, the flame front acquires the nature of turbulent combustion. The flame front propagates much faster with increasing crankshaft speed. That is, the scenarios of mixture burn-out over time also depend on the speed mode.

There are various methods for accelerating the flame front propagation and accelerating the flame kernel formation in gas engines with ultra-lean mixtures. There are two concepts for mixture preparation in the combustion chamber at the end of the compression cycle - operation on a homogeneous mixture or operation with intentional mixture stratification.

For example, to optimize operation on a lean homogeneous mixture, ignition systems with an increased discharge energy are used. Additionally, depending on the volume of the main combustion chamber, different concepts of ignition are applied [2,8]:

- direct ignition (DI) with one or two spark plugs. In gas engines with a capacity of up to $1 \mathrm{MW}$, DI is mainly used;

- ignition with passive prechamber (PPC), which is structurally realized in the capsule of a special spark plug or in the cylider head. By applying the PPC, an increase in the reliability of the flame kernel formation can be achieved;

- ignition with gas feeded prechamber (GFPC). By applying the GFPC, a significant acceleration of flame front propagation in the space of the main combustion chamber of a larger volume is achieved [2,8]. GFPC is used in gas engines with a large volume of cylinders - usually in gas engines with a capacity of more than $5 \mathrm{MW}$.

Similarly to automotors with direct injection of light fuel, the concept with mixture stratification in the combustion chamber according to a certain pattern and direct ignition by one plug located in the region of rich mixture can be applied.

Also, combustion can be accelerated by the addition of hydrogen, which has not yet found wide application in the operation of industrial gas engines. However, within innovative technical solutions for the harmonization of consumption cycles in the grid and energy generation from alternative energy sources, it is known that hydrogen is used as the main fuel of an industrial gas engine as an energy carrier stored in a tank and obtained by electrolysis during peak power generation (for example, by wind power plants). Hydrogen as fuel makes it possible to significantly expand the lean limits without the need for ignition systems with an increased discharge energy and/or major structural changes in the engine.

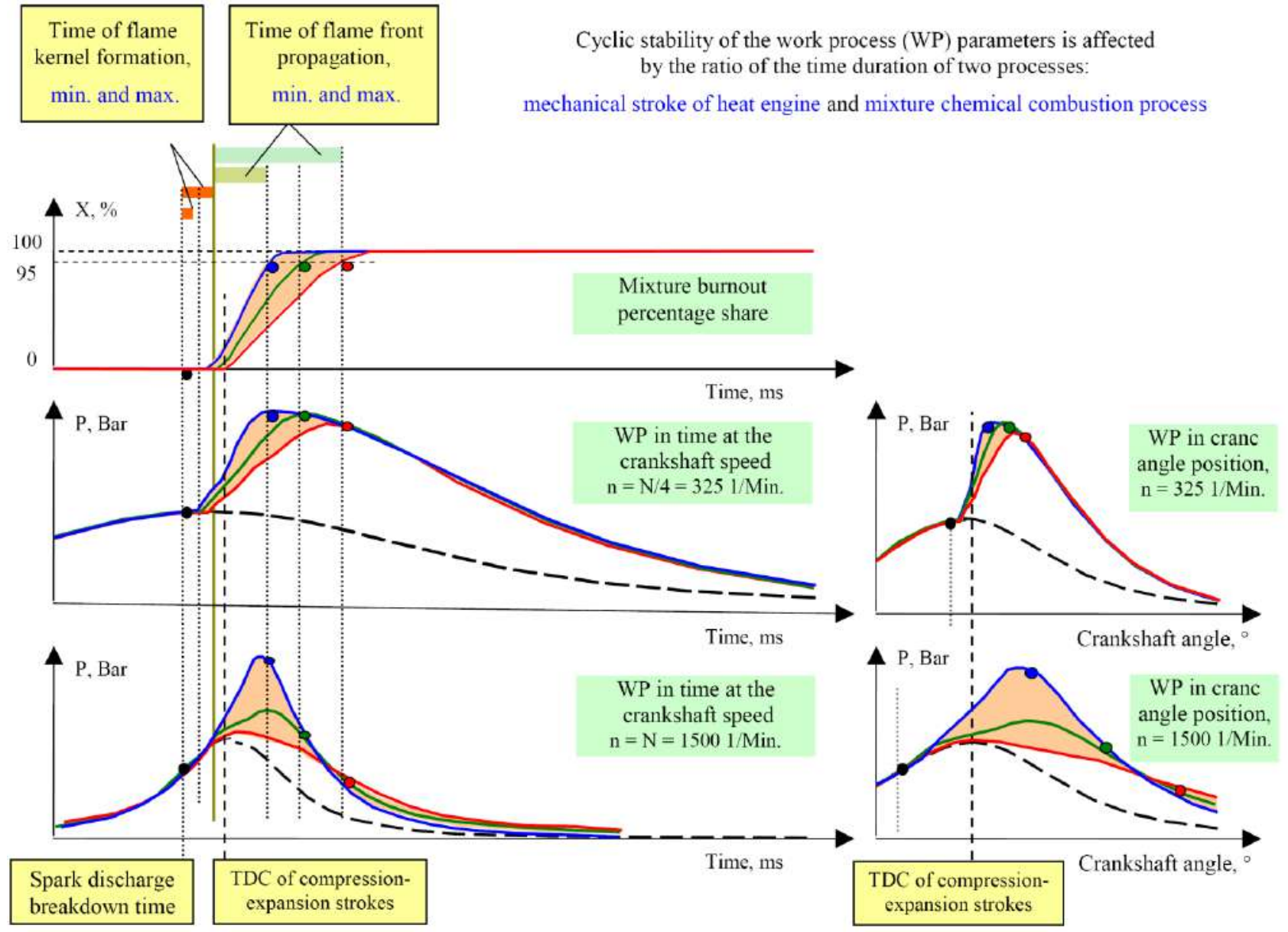

Fig. 4. Example for the theoretical representation of the interrelation between the variation of the combustion process time and, as a consequence, the variation of the work process (WP)

in two different speed modes 
Any technology will have limits. For the practical optimization of the combustion process in a specific engine due to the use of any solution (for example, on ignition), it is necessary to analyze the experimental data of the work process on pressure changes in the combustion chamber, that is, the processing of the detailed indicator diagram (ID) of an individual cycle in the engine cylinder.

\section{3. Automated processing of ID of individual cycles} for collecting the WP parameters in the database and their subsequent statistical processing

In the ID, three combustion phases can be identified (Fig. 5) [1]:

- flame kernel formation ( $\mathrm{C} 0-\mathrm{C} 1$ interval), where the burn-out of the charge is no more than $8 \%$;

- flame front propagation ( $\mathrm{C} 1-\mathrm{Z}$ interval), where the burn-out of the charge is $70-80 \%$. The phase begins with the active heat release (the point of separation from the compression line $\mathrm{C} 1$ ends with a pressure peak (point $\mathrm{Z}$ );

- mixture afterburning, where the burn-out of the charge is $10-15 \%$.

To estimate the time of the flame kernel formation and the rate of flame front propagation in a separate engine cycle, it is possible to perform a mathematical processing of the ID, i. e., calculation of heat release in order to obtain the dependence of the mixture fraction burned on the crankshaft angle (CSA) $\Theta$. Thus, using the dependence of the mixture fraction burned $X(\Theta)$, it is possible to clearly distinguish three combustion phases and measure their time. However, a less accurate alternative is the recognition of combustion phases in the indicator diagram, as described above.
The moment in which the burnout of the charge is $50 \%$ is generally called the combustion center and denoted MFB50 (mass fraction burned) [4]. For the optimum WP, the MFB50 moment should be at position $\Theta$ approximately equal to $12^{\circ}$ cranc after the top dead center (TDC) [4].

According to [4], the combustion rate can be estimated from the burnout time of $50 \%$ of the mixture - the interval from the beginning of the spark ignition discharge to the MFB50 point, found by calculating the heat release from the ID (Fig. 5).

The time of the flame kernel formation can be estimated by measuring the interval from the beginning of the spark discharge (electric breakdown event) to the notable heat release, according to the dependence of the mixture fraction burned $X(\Theta)$.

Also, it is possible to compare the estimation of the time of the flame kernel formation by analogy with the ignition delay - the interval from the beginning of the spark discharge (electric breakdown) to the notable heat release as a certain "point of separation" of the ID from the compression line (without combustion) in the current operating mode of the engine. To find the "separation point" in the ID, it is possible to calculate the pressure difference function $\Delta P(\Theta)$ - the ID for the current cycle and the compression line in the engine operating mode. The compression line should be recorded in the process of artificial misfire (spark discharge blocking) in one engine cycle in the current operating mode, which can be automated as a calibration function of the measurement system. The separation point can be found automatically from an increase in the pressure difference $\Delta P$ above a certain trigger level of a small value.

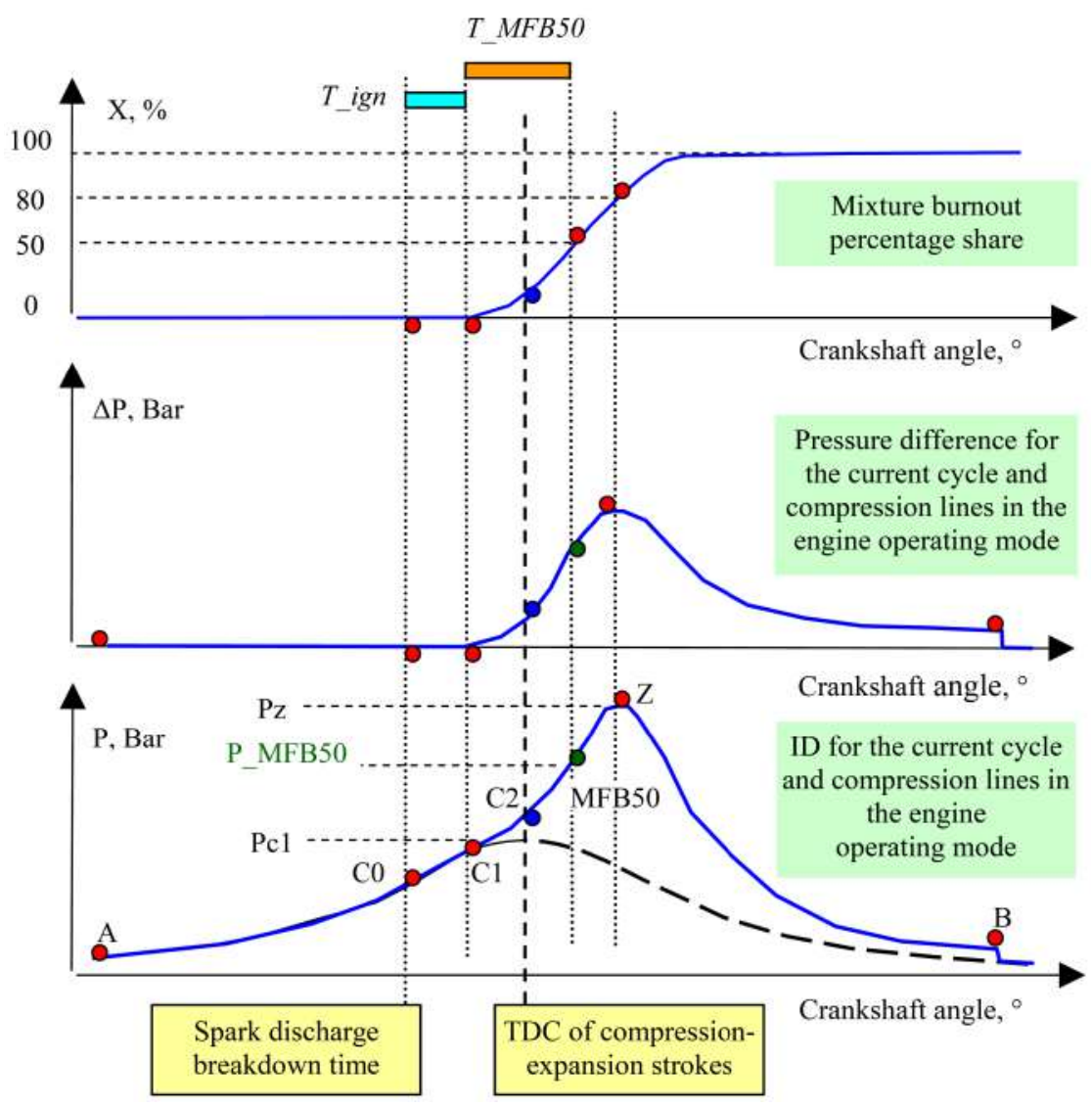

Fig. 5. Automated processing of the indicator diagram to assess the main WP characteristics, estimate the ignition delay and mixture burn-out rate 
The flame propagation rate can be estimated from the burnout time of $50 \%$ of the mixture - the interval from the end of the flame kernel formation to the MFB50 point.

For a simplified description of the combustion process using the IDs of each cycle, we take into account three important parameters (Fig. 5) [4]:

$T_{I G N}$ - ignition delay - the interval from the beginning of the spark discharge (electrical breakdown) to the notable heat release as a certain "point of separation" of the ID from the compression line (without combustion) in the current operating mode of the engine. It would be more correct to talk about the point of separation from the compression line.

$T_{M F B 50}$ - the time from the beginning of heat release to the moment of burn-out of $50 \%$ of the charge (MFB50).

An automated measurement processing system should ensure fast processing of IDs and determination of a number of parameters of each cycle:

- combustion time - $T_{I G N}, T_{M F B 50}$

- work process $-P i, P_{Z}$, as well as $P_{C 0}$ at the start of the spark discharge, $P_{C 2}$ in the TDC, pressure at the crankshaft position at the bottom dead center of the beginning of the compression cycle $P_{A}$ and the end of the expansion cycle $P_{B}$;

- temperature and pressure $\left(T_{I N}, P_{I N}\right)$ in the intake manifold
- mixture composition $\lambda$ according to the air and gas flow rate;

- crankshaft speed $n$;

- temperature $T_{E X T}$ in the exhaust manifold of the displayed cylinder.

With an automated cyclic synchronous collection of results in the database (DB) for a number of cycles in one operating mode of the engine and subsequent statistical processing of $\mathrm{DB}$ data, it is possible to determine the relationship between the combustion time parameters $\left(T_{I G N}\right.$, $\left.T_{M F B 50}\right)$ and the WP parameters $\left(P_{i}, P_{Z}, P_{A}, P_{B}, P_{C 0}, P_{C 1}\right.$, $\left.P_{C 2}, P_{M F B 50}\right)$. It is also possible to construct histograms for determining the law of distribution of quantities and checking the constancy of the initial conditions (speed, mixture composition, $\left.T_{I N}, P_{I N}, P_{A}, P_{C 0}\right)$. In case of strong instability of the initial conditions, the experiment should be improved.

It should be noted that for a comparative study of the causes of CI in different operating modes of the engine, not strict compliance of $T_{I G N}, T_{M F B 50}$ with the chemical burn-out of the mixture is of interest, but their relative variation. Thus, the invariance of the measurement and data processing method in all investigated operating modes of engines is necessary, which is implemented by the automated system.

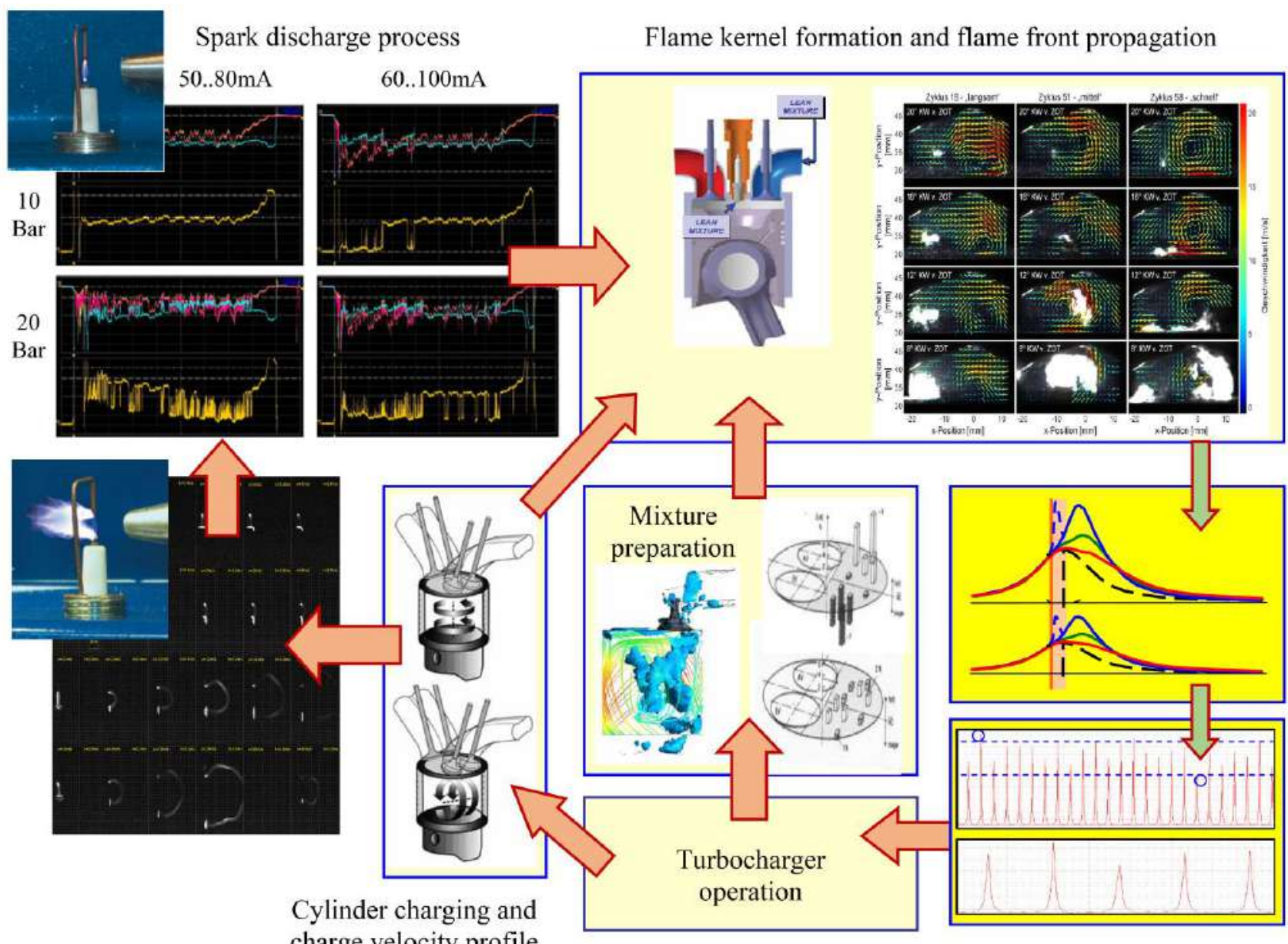
charge velocity profile

Fig. 6. Interrelations of a number of factors in a whole system - processes that form conditions before ignition of mixture and process of subsequent combustion. Variations in the conditions before ignition of mixture affect the variations in the process of the flame kernel formation and subsequent combustion 
4. 4. Relation of irregular changes in the combustion process and pocesses before ignition of mixture

In practice, the work process parameters, taken for a number of cycles in the mode, are a physical values with a random distribution according to a certain law. However, all processes are more or less interrelated. (Fig. 6). The initial conditions before the flame kernel formation - mixture composition and stratification degree, charging and profile of mixture motion in the combustion chamber, energy supply through the ignition system - can vary from cycle to cycle for a number of reasons $[2-4,8]$. The parameters of these processes can be described by values with a random distribution according to a certain law, which corresponds to the actual state in practice. For example, in the case of processes with a low level of cyclic instability, the dispertion and width of the distribution histogram of the characteristic values will tend to zero.

\section{5. Influence of turbocharger operation on the CI of} the charging process

The first example of the relationship - in a gas engine with a turbocharger, misfires lead to changes in the energy of exhaust gases and in the turbocharger operation from cycle to cycle, which causes irregular changes in the charge pressure and cylinder charging degree from cycle to cycle. However, depending on the engine air supply system structure, influence on mixture composition is also possible, i.e., irregular changes (fluctuations) in the cylinder charging and mixture composition from cycle to cycle due to the increased misfire rate.

By the cyclic measurement of pressure $P_{I N}$ and temperature $T_{I N}$ in the intake manifold, it is possible to estimate the constancy of the cylinder charging during the intake process of cylinder.

\section{6. Influence of fuel mixture stratification degree on} the $\mathrm{CI}$ of the combustion process

The second example is the influence of mixture stratification degree (Fig. 7) [2, 4]. At the time of the spark discharge, the energy for ignition (transferred in the form of a portion of heat and dissociation of the gas matter) is transferred to the local region of the gas medium. Under conditions of charge motion at a high mixture stratification degree, the spark discharge can occur both in richer and in leaner regions of the mixture, which will cause irregular changes in the process of the flame kernel formation according to a random law [4].

The engineering solution of the supply system is responsible for sufficient homogeneity of the mixture. The supply system design optimized for operation on a stoichiometric mixture (for example, gas fuel injection similar to automotive engines) may be unsatisfactory for stable operation on an ultra-lean mixture due to the insufficient homogeneity of the prepared mixture in the combustion chamber in the end of compression [2,4].

In [4], the laser measurement method, based on the luminescence principle, was applied to study the distribution of mixture composition in the combustion chamber in the end of the compression cycle on a laboratory single-cylinder engine with quartz glass windows. This method cannot be applied to a serial engine, and here one has to be limited to the cycle-by-cycle recording of the average mixture composition $\lambda$ calculated by the air $V_{A I R}$ and gas fuel $V_{G A S}$ flow rates.

When the gas engine operates at the lean limit, partial misfires are possible. Therefore, the readings of the broadband $\lambda$ sensor cannot be used in the experimental conditions as reliable data. The only reliable method for determining the air-fuel ratio of the mixture, regardless of the success of combustion of this mixture in the cylinder, is to calculate $\lambda$ of the prepared mixture by the air and gas fuel flow rate. The accuracy of $\lambda$ measurement depends on the accuracy of the flow rate measurement.

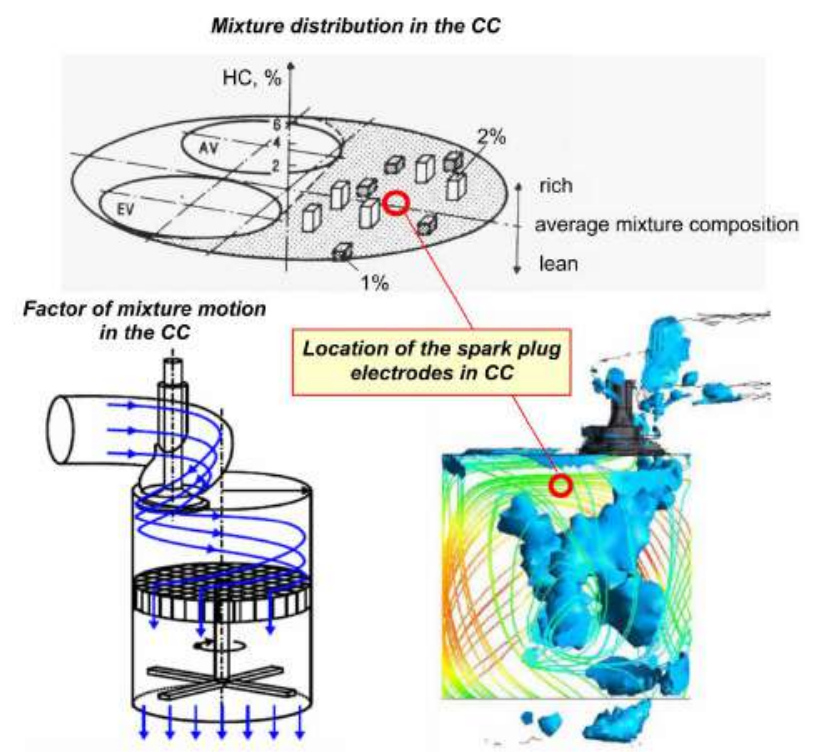

Fig. 7. Influence of the stratification degree (homogeneity) of the prepared mixture on the instability of the flame kernel formation $[2,4]$

However, in an automated system of data collection on the test bench, it is possible to supplement each engine cylinder with a separate broadband $\lambda$ sensor and take into account the relative change of signals as a deviation from the average value of $\lambda$, calculated by the air and gas fuel flow rates. This will allow assessing the level of cyclic instability of the mixture preparation process, on condition of complete combustion.

In the conditions of the test bench on a serial engine, the distribution profile of mixture composition in the combustion chamber remains unmeasured. However, by central mixture formation, for example, by means of a air-gas mixer of the ejector supply system and an intake manifold of sufficient length, it is possible to create a mixture with good homogeneity before the cylinder charging.

4. 7. Influence of the instability of the charge velocity profile on the $\mathrm{CI}$ of the combustion process

In [4], the laser method of measuring the charge velocity at each point of space synchronously with the crankshaft position on a laboratory single-cylinder spark-ignition engine with quartz-glass windows was applied. Shooting of the velocity profile (VP) and flame front development in the combustion chamber (CC) it the end of the compression cycle was performed. Shooting was performed synchronously with the crankshaft angle and gave an information about dynamics of changes. In [4], it was found experimentally that:

- for 100 engine cycles in the same operating mode of the engine, various options of the $\mathrm{VP}$ of the charge in the $\mathrm{CC}$ are observed (Fig. 8);

- the velocity profile of the charge in the $\mathrm{CC}$ has a direct effect on the process of flame front propagation (burn-out of the main part of the mixture), but there has been no significant influence on the flame kernel (s) formation. 
Cycle No. 18: "slow combustion scenario"
Cycle No. 51: "average-speed combustion scenario"
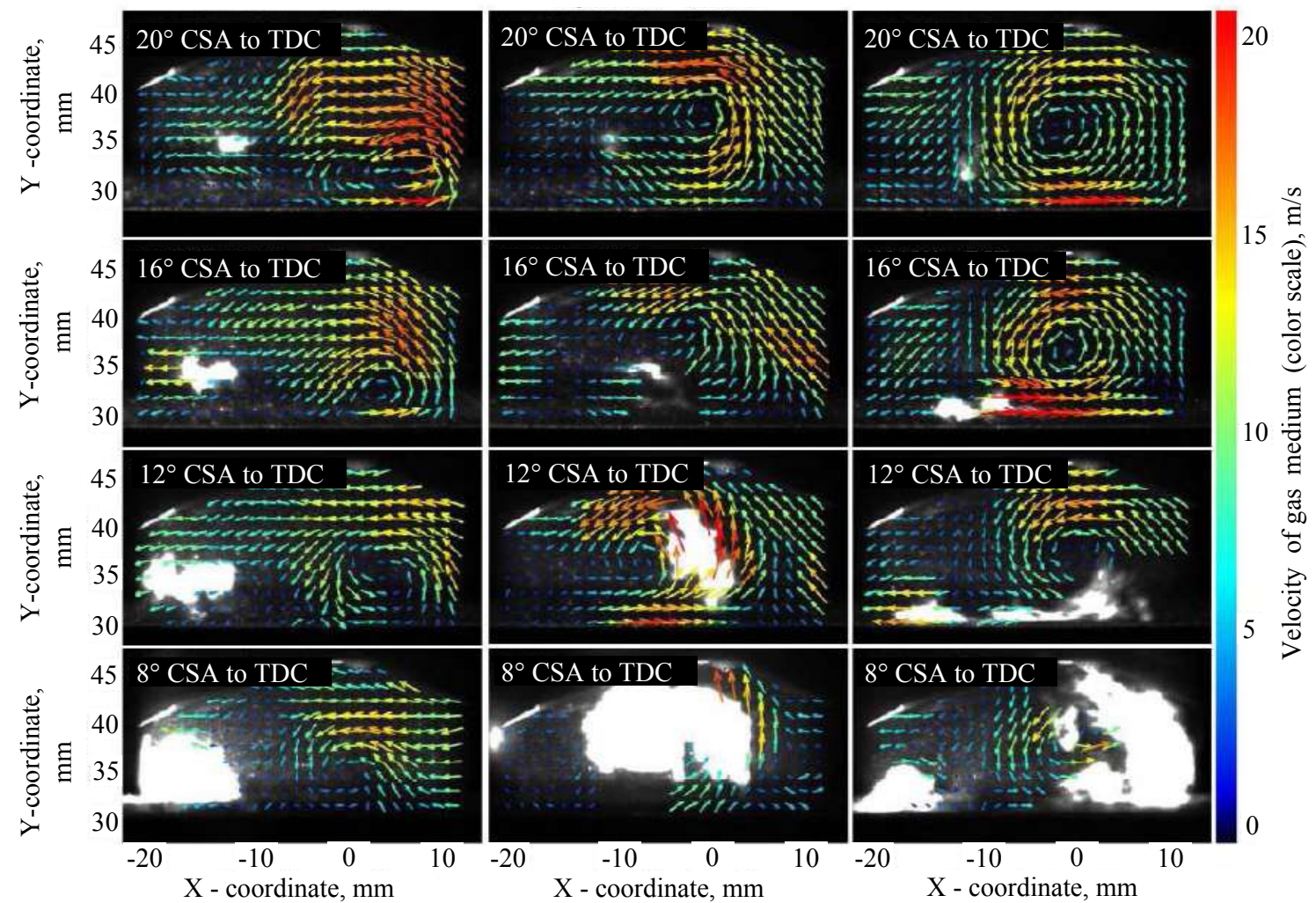

Cycle No. 58:

"rapid combustion scenario"

Fig. 8. Effect of the velocity profile of the charge in the combustion chamber on the flame front propagation process, i. e. the process of burn-out of the main part of the charge [4]

From to the presented shooting of three combustion scenarios, it can be seen that the flame kernel, from which the front propagates, moves along with the gas medium. At the same time, the conditions for the front propagation and/or even division into several new kernels are formed in dynamics. The position of the kernel (kernels) in the $\mathrm{CC}$ changing with the mixture motion and determines the paths which should be passed by the flame front in different directions. Thus, the mixture burn-out time strongly depends on the charge VP. It is the VP instability as the main factor that causes the fluctuation of the time of burn-out of $70 \%$ of the charge, i. e., it directly affects the CICP.

On serial engines, which are often used on test benches, it is not possible to implement the method of measuring the VP in the CC, i. e. the VP of the charge in the CC will remain unmeasured. As is known, the geometry of the intake manifold and the shape of the $\mathrm{CC}$ have a significant effect on the $\mathrm{VP}$ of the charge in the $\mathrm{CC}$.

4. 8. Influence of instability of spark discharge parameters on the $\mathrm{CI}$ of the combustion process

The cyclic instability of the spark discharge - spontaneous fluctuations of the discharge parameters from cycle to cycle - entails instability of the process of the flame kernel formation (Fig. 6). Due to the complexity of interrelations, the process of energy portion transfer to form the flame kernel and the causes of its cyclic instability will be discussed in detail in the next section.

\begin{abstract}
5. Analysis of the influence of the form of supply and amount of electric discharge energy at the spark plug electrodes on the process of the primary flame kernel formation and its CI level
\end{abstract}

\section{1. Spark ignition}

The electric discharge of the spark ignition system is a means of timely transfer of the energy portion (in the basic share in the form of heat portion) to the local area of the gas medium in order to initiate the primary flame kernel. Three phases or main sections of the current-voltage discharge characteristic - electric breakdown, arc phase and glow discharge phase - are present in each spark discharge in different proportions and intensities, and are also used for energy transfer. The share of transferred energy and/or intensity of each phase depends on the operation principle of the spark ignition system (SIS) and/ or parameters of its high-voltage components [3, 11, 12]. The way of energy transfer - from the electronic unit output, the discharge at the spark plug (SP) electrodes in the combustion chamber to the portion of heat transferred to the gas medium is considered below (Fig. 9). However, the process of energy transfer, both in the secondary ignition circuit and in the gas medium in the $\mathrm{CC}$, is subject to various factors of influence and exhibits cyclic instability under the same initial conditions.

For piston gas engines, especially in the industrial application of cogeneration units, it is necessary to ensure a sufficiently long service life of the SP in accordance with the maintenance schedule. To reduce the erosion of the surface material of the electrodes, SIS with energy transfer by means of a long glow 
discharge and, if possible, minimum arc discharge phase are used [11, 13-15]. Below, we consider the factors of instability of energy transfer in the SIS with the mentioned concept:

- heat transfer of three discharge forms to the gas medium and heat loss at the SP electrodes;

- spontaneous transitions between the glow and arc discharge phases;

- influence of mixture velocity.

\section{2. Heat loss at the spark plug electrodes}

The discharge power and heat transfer of the discharge energy to the surrounding gas medium depend on the type of discharge [7, 9, 11]. By definition, the discharge type determined by the mechanism of emission the main charge carriers from the material of the electrodes into the gas medium $[7,15]$.

Thus, the glow discharge is characterized by the distribution of the current density over the entire surface of the electrodes (low current density) with emission under the action of the photons radiation and electrical field (Fig. 10).

The arc discharge is characterized by a high current concentration exclusively in the super-hot small point of the cathode surface "cathode spot" due to thermoelectronic emission [6-9, 15] (Fig. 10). The phenomenon of thermoelectronic emission proceeds like a heated cathode in electrovacuum devices, but with the arc discharge it is localized in the "cathode spot". A stable physical state is formed on the electrode surface in a relatively small area called the "cathode spot": local heating of the electrode surface causes a high current density, and vice versa - a high current density causes surface heating in the local area. The current density outside the "cathode spot" is very small. As a result, almost the entire cathode current is concentrated in the cathode spot and this conduction mechanism corresponds to the arc discharge.
$\mathrm{Z} \approx 5 \mathrm{kOhm}(\mathrm{DC})$

high-voltage wire-wound resistor for increased impedance in the HF area to reduce the current peak

of the spark discharge arc phase $[14,16,17]$
Effect of the gas medium motion on:

- glow discharge plasma channel elongation [12] - discharge power and energy - heat transfer between discharge channel, gas medium and SP electrodes

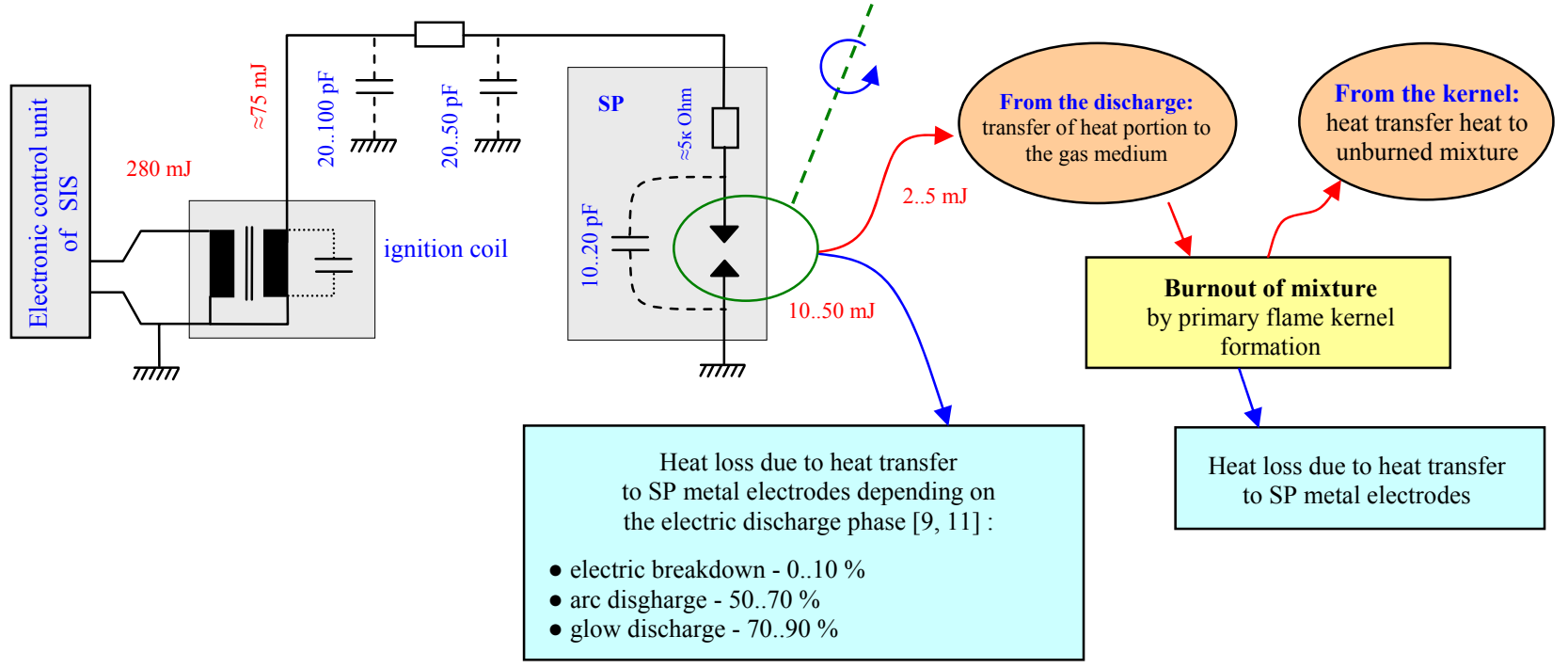

Fig. 9. Example of capacitor discharge SIS and way of energy transfer. Quantities of energies and electric values are taken as an example of a capacitor discharge SIS for industrial lean burn gas engines, used in cogeneration plants [9, 11-19]

$$
\begin{gathered}
\mathrm{dP} / \mathrm{dX} \\
=\mathrm{I} \cdot(\mathrm{dU} / \mathrm{dX})
\end{gathered}
$$

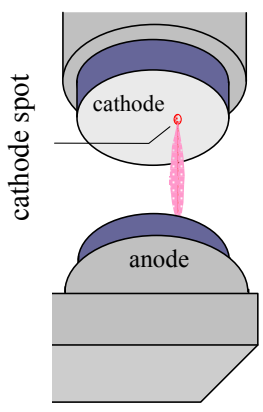

$a$

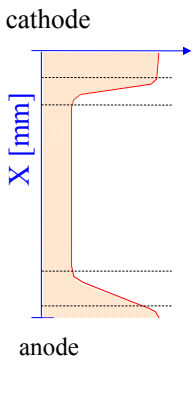

$b$

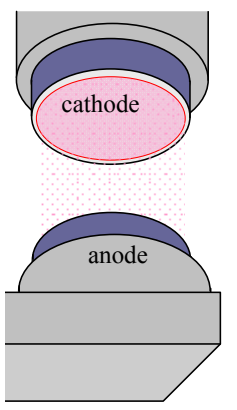

$c$
$\mathrm{dP} / \mathrm{dX}$ $=\mathrm{I} \cdot(\mathrm{dU} / \mathrm{dX})$

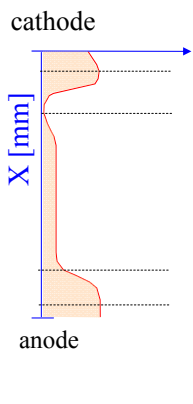

$d$

Fig. 10. Sketch of the plasma channel and graphs of power distribution of electric losses of arc and glow discharges in the stationary gas medium: $a$ - plasma arc discharge channel with a high current density and current concentration in the hot cathode spot of thermoelectric emission [8]; $b$-conditional graph of power distribution of the heat release by the arc discharge channel plasma [15]; $c$ - plasma channel of the glow discharge with a low current density over the entire area of the electrodes [8]; $d$ - conditional graph of power distribution of heat release by the glow discharge channel plasma [15] 
With the discharge in the stationary gas medium, each of the main conduction mechanisms - glow and arc - differs in the distribution of the released power in space - over the area and along the spark gap (Fig. 10) [15]. This affects the share of heat loss due to thermal conductivity to colder electrodes [9, 11]:

- electric breakdown - loss of $0 . .10 \%$;

- arc discharge - loss of $30 . .50 \%$;

- glow discharge - loss of $70 . .90 \%$.

It is not possible to measure the discharge heat transfer coefficient at the SP electrodes in actual operating conditions of the engines. However, experiments in the compressed air medium to estimate the transferred portion of heat by pressure increase can be carried out [9].

\section{3. Spontaneous transitions between the glow and} arc discharge phases

In the production of many discharges, spontaneous transitions between the arc and glow phases may occur in the stationary compressed air gas medium and with the same initial conditions in the primary ignition circuit (Fig. 11) [6, 8].

In the framework of the research works $[18,19]$, experiments of high-voltage components of the Heinzmann $\mathrm{GmbH}$ company, 2014 were performed on the test bench using the "PHLOX-II Multispark" experimental ignition system as a tool for spark discharge production.

According to [8], the observed spontaneous phase transitions - from glow to arc and back - are caused in practice

Currents of the SP electrodes and /or of secondary winding of the ignition coil $\boldsymbol{I}_{s p}$

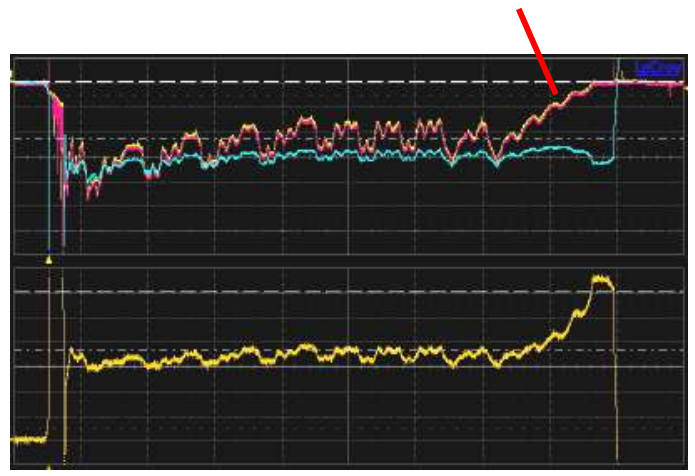

$a$

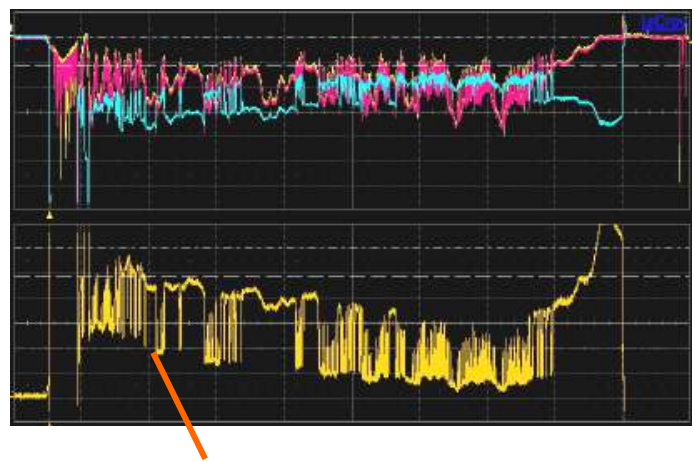

Voltage at the SP electrodes

in the chamber with compressed air by the processes of formation and destruction of the oxide film of the cathode metal surface at the site of the hot cathode spot. On the other hand, according to [7], in the current-voltage characteristic (CVC) of the SP gas discharge, with the SP schemes used (Fig. 8), for each of the main conditions of the gas medium, two stable points (1 and 3 ) can be present in the sections of glow and arc discharges (Fig. 12). The increase in the arc discharge rate causes additional erosion of the electrodes [8].

In the SIS with the concept of using a long glow discharge, even with the relative constancy of the current pulse of the secondary circuit and the same initial conditions, the mentioned random nature of the discharge phase transitions causes various options of the shape of the voltage pulse at the SP electrodes. Accordingly, from cycle to cycle, there are arbitrary changes in the energy portion delivered by the discharge to create the flame kernel. Consequently, the portion of energy transferred by the glow discharge is a quantity that varies in accordance with a random law, but the law of distribution of this quantity (Fig. 13) depends on:

- the gas medium density and temperature, flow velocity in the region of the SP electrodes [9, 12, 14, 19];

- the shape of the current pulse at the SP electrodes and the parameters of the high-voltage components of the secondary circuit, which are formed in the SIS [9, 11, 12, $14,18,19]$

- the geometry of the SP electrodes [9, 14,20].

Voltage of the secondary winding of the ignition coil

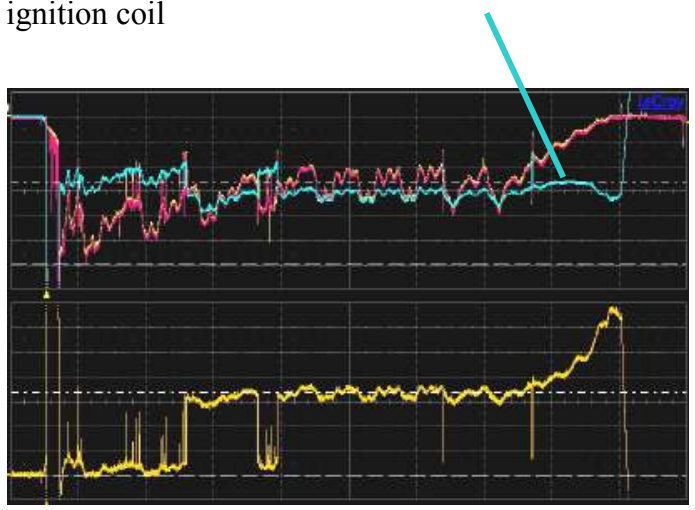

$b$

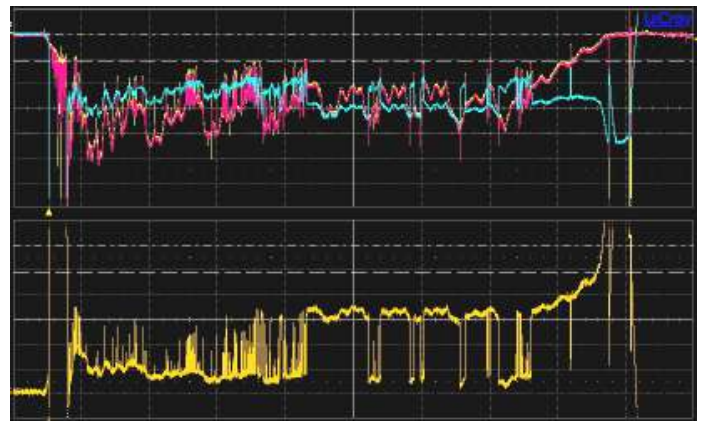

c

$d$

Fig. 11. Oscillograms of current and voltage of glow discharge at the electrodes (flat, Ø2.5mm) of spark plug BERU KB77WPCC in the compressed air medium 10 and 20 bar at different amplitudes of long current pulse: $a-$ in the compressed air medium 10 bar, SP electrode current $I_{s p}=50 . . .80 \mathrm{~mA} ; b-$ in the compressed air medium 10 bar, SP electrode current $I_{s p}=60 \ldots 100 \mathrm{~mA} ; c-$ in the compressed air medium 20 bar, SP electrode current $I_{s p}=50 \ldots 80 \mathrm{~mA} ; d-$ in the compressed air medium 20 bar, SP electrode current $I_{s p}=60 \ldots 100 \mathrm{~mA}$ 


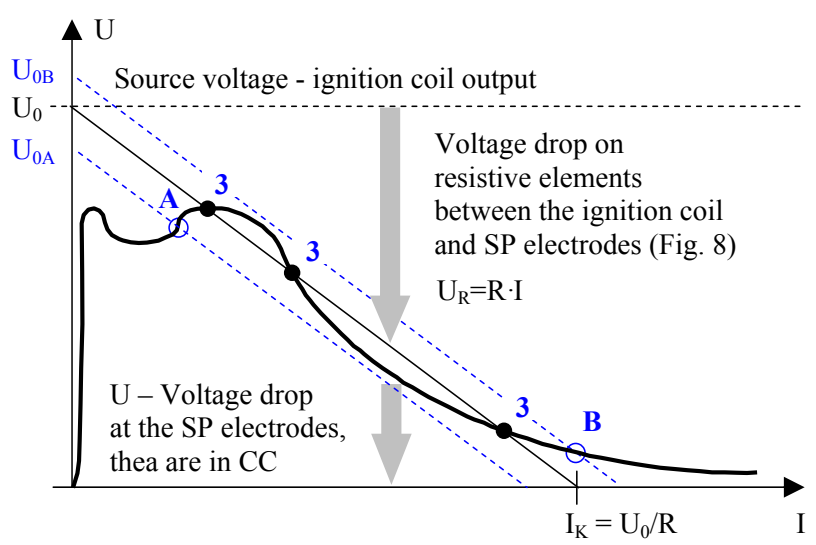

Fig. 12. Graphical solution to finding of the operating point of the secondary ignition circuit on the CVC of spark discharge [7]

In the engine $\mathrm{CC}$, the density and temperature of the gas medium change with the piston motion during a long spark discharge. So, at a crac speed of $15001 / \mathrm{min}$, the time of the discharge, for example, of the capacitor SIS, is about 500 microseconds and corresponds to $5^{\circ} \mathrm{CSA}$.

The changes of the IT and charging degree at the inlet (load) have the same effect.

Theoretically, it is possible to achieve the maximum discharge power at the glow phase without the second point on the VAC (without the "B" point in Fig. 12). This can be achieved by automated adjustment of the voltage level $\left(U_{0 A}\right)$ at the ignition coil output only under the condition of long engine operation in the constant mode, for example, when using an industrial gas engine of the cogeneration unit.

This condition can correspond to the optimum and stable operation of the SIS without spontaneous transitions of the discharge phases.

It is possible to adjust the SIS and/or to select the components for the optimum discharge shape at the plug electrodes that meets the following criteria:

- reliable transfer of a portion of energy to the gas medium above the required ignition energy (RIE);

- acceptable service life of plugs due to erosion of the electrodes. For the optimum adjustment of the ignition system to the existing operating conditions of the lean burn gas engine, a suitable experimental estimation technique is needed.

The estimation of the energy portion produced by the spark discharge can be made using the histogram of the measured energy portions in the glow $E_{G L O W}$ and arc $E_{A R C}$ discharge phases taken for 1,000 cycles in the engine operating mode (Fig. 13).

However, the form of energy portion supply also has an effect on the probability and formation rate of the primary flame kernel. Thus, out of several spark discharges at the SP electrodes with a time of, for example, 700 microseconds ( $7^{\circ}$ cranc at a rotation speed of $1,5001 / \mathrm{min}$ ) with the release of the same energy portion, the discharge with the transfer of most of the energy portion exactly in the beginning of spark discharge has the advantage in the formation rate of the flame kernel. To evaluate the form of energy supply, an integral criterion is needed that takes into account the process of the flame kernel formation in accordance with a certain mathematical model, for example, as discussed in [20]. This criterion can also be found experimentally by bench tests on a gas engine using the methods of correlation of a set of measured values.
Evaluation of erosion of the electrodes can occur similarly - according to the histogram of the values of the past charges in the arc $Q_{A R C}$ and glow $Q_{G L O W}$ phases, taken for 1,000 discharges in the engine operating mode.

Each SIS has limits on the peak of the high-voltage impulse for the electric breakdown in the spark gap. The breakdown voltage in the spark gap of the spark plug will permanently increase due to the surface wear of the SP electrodes, i. e., changes in the electrode surface shape [7]. Estimation of the stress on the insulation of high-voltage components can occur according to the histogram of the values of electric breakdown voltages $U_{B D}$ for many discharges in the constant operating mode of the gas engine [7].

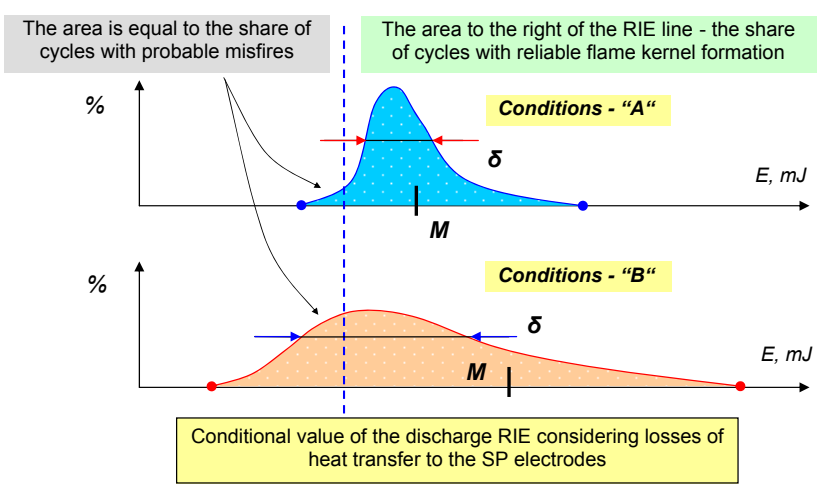

Fig. 13. Illustration of the distribution histogram of the discharge energy for 1,000 engine cycles with constant initial conditions

It should be mentioned that the equipment for engine fault diagnosis (for example, engine testers) is capable of recording and displaying oscillograms of voltages from the ignition coil output, various sensors to the operator and reading indicator diagrams. The main task of engine testers is to enable a qualitative evaluation to compare the current process with a certain reference, corresponding to a working engine condition and to reveal a fault through the interpretation of oscillograms. For engine testers, there is no direct need to quantify physical processes.

The proposed measurement system is designed primarily for research tasks in bench tests of gas engines at the ignition limit in order to expand the lean limits. It is necessary to take into account the manifestation of cyclic instability, as described above. The measurement system should allow a quantitative assessment, if possible, of all physical processes preceding ignition and, of course, a quantitative assessment of the work process in each engine cycle.

For example, the function of the measurement system associated with measuring the spark discharge characteristics in each engine cycle:

- to calculate voltage $U_{S P}(t)=U_{I C}(t)-I_{I C}(t){ }^{*} R_{S P}$ at the spark plug electrodes in CC (Fig. 9) from signals of the voltage and current on the ignition coil, i. e. voltage after the resistor, built in the spark plug with resistance $R_{S P}$ (which cannot be directly measured on a running engine) [19];

- to automatically interpret the discharge current signal $I_{I C}(t)$ and distinguish discharge phases - arc and glow;

- to calculate the resistance of the heated spark plug $R_{S P}$ by a certain technique. It is known that the resistance of the resistor in the plug depends on the temperature in the plug and has its own production tolerance; 
- to calculate the discharge power $P_{S P}(t)$ at the electrodes for each of the discharge phases. To integrate the power to produce a portion of energy $\left(E_{G L O W}, E_{A R C}\right)$ and current to produce a portion of the charge electrodes $\left(\mathrm{Q}_{G L O W}, Q_{A R C}\right)$ passed through the electrodes. To measure the time of each of the phases $\left(T_{G L O W}, T_{A R C}\right)$;

- to distinguish the electric breakdown event $t_{B D}$ from the discharge current signal $I_{I C}(t)$ and measure the breakdown voltage as $U_{B D}=U_{I C}\left(t=t_{B D}-300 \mathrm{~ns}\right)$.

To quantify the physical quantities characterizing the electric discharge at the electrodes in the engine combustion chamber, an apparatus is needed that is capable of producing fast and fairly accurate measurements of voltage and current exposures of the secondary ignition circuit in the conditions of the engine test bench. It should also perform the subsequent rapid numerical processing of the recorded signal exposures for each engine cycle and synchronous collection of the results in the database.

This requires a specialized digital measurement system intake his hardware and software parts, which involves optimization in the operation process. This measurement system is under engineering development and can be considered in detail after obtaining reliable practical measurement results in the experiment.

\section{4. Influence of mixture velocity}

With the motion of the gas medium, there is a mechanical transfer of the plasma channel of long time glow discharge (Fig. 14). According to the results of experiments in moving air under normal conditions [12], it is found that there is an increase in the glow discharge voltage with an elongation of the plasma channel (Fig. 15).

With high flow rates and long time glow discharge, strong elongation leads to the channel breakage and, as a consequence, to the discharge termination or a new breakdown with the formation of a new channel. The resistance to discharge termination at high flow rates increases with increasing discharge current at SP electrodes. The level of the discharge current should be selected when adjusting the SIS to stable operation at full load with the largest applicable leaning of the mixture of the gas engine of the given model. The simplest characteristic can be the discharge time in the arc $T_{A R C}$ and $T_{G L O W}$ phases.

Taking into account the SP location in the combustion chamber, the geometry of the SP electrodes and the charge velocity profile, a significant influence on the process of transferring a portion of energy to the gas medium for the primary flame kernel formation is possible. The analysis of voltage and current signals at the SP electrodes in actual operating conditions of engines allows measuring the energy and power of the electric discharge. Theoretically, it is possible to estimate approximately the influence of the gas medium velocity using the oscillogram of the glow discharge voltage to adjust the SIS to the given mode of the given model of gas engines by selecting the shape of the current pulse of the SP electrodes. However, it is not possible to measure the coefficient of heat transfer of the discharge to the gas medium in actual operating conditions of the engines.

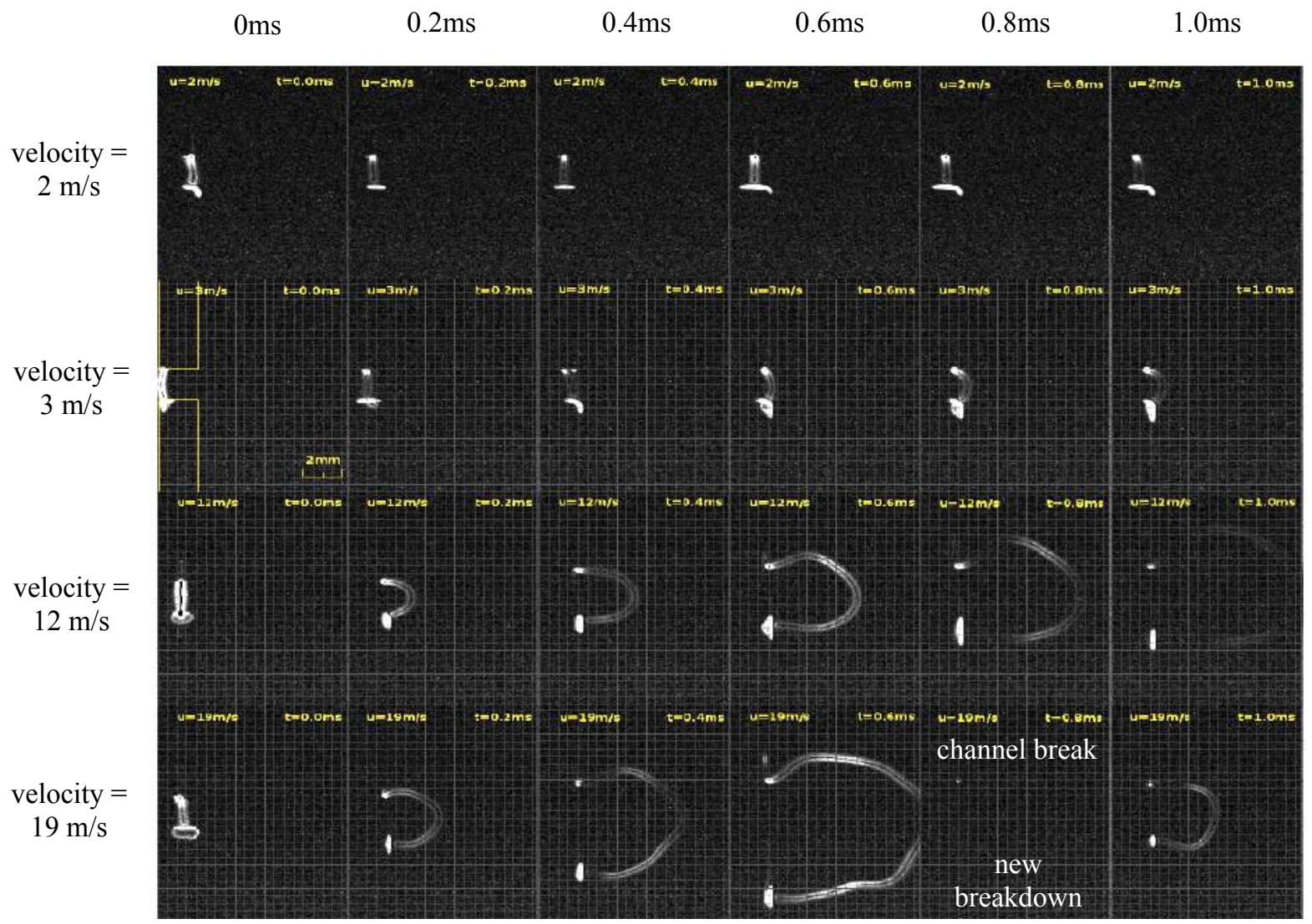

Fig. 14. Process of changes in the length of the glow discharge plasma channel over time at different velocities of the gas medium [12] 


\section{5. Probability of the flame kernel formation}

Through experimental research in the "bomb", the influence of various factors on the probability of the flame kernel formation was studied:

- pressure and composition of the methane-air mixture (Fig. 3) [5];

- energy of short spark discharge for ignition of hydrogen-air mixtures of different composition (Fig. 16) [10].

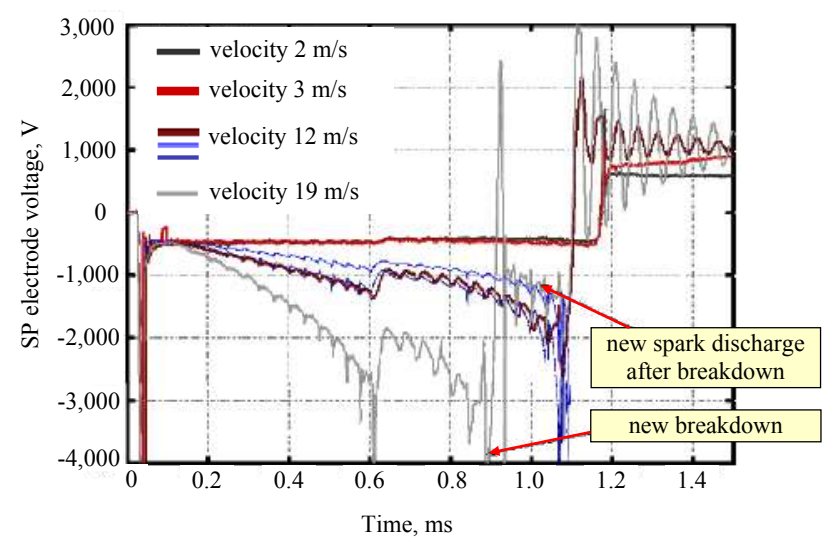

Fig. 15. Oscillograms of the glow discharge voltage at different velocities of the gas medium [12]

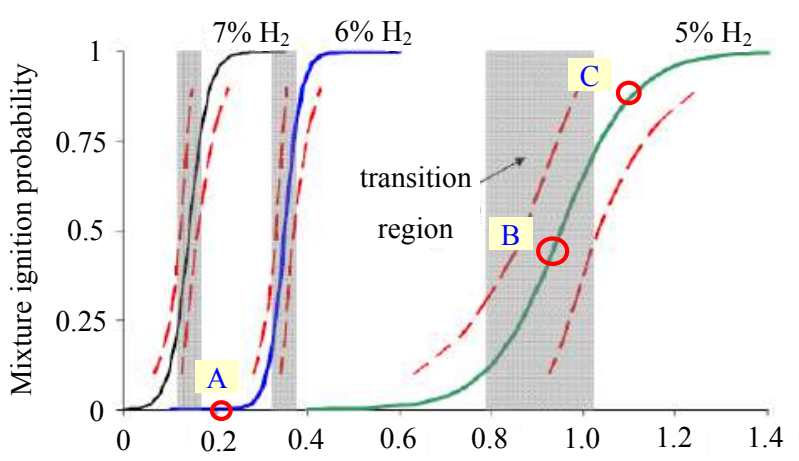

Heat portion transmitted by the discharge in to mixture, $\mathrm{mJ}$

Fig. 16. Experiments in the "bomb", probability of the primary flame kernel formation by short arc discharge [10]

It is important to note that mixture ignition is of a probabilistic nature and the probability increases with a larger portion of heat introduced by the discharge into the mixture $[5,10]$. For gas engines, the term MIE (minimum of ignition energie), where existing mathematical models imply some minimum portion of heat for igniting a mixture of the given composition is used. In the field of fire and explosion safety, the concept of MIE represents energy with ignition probability of $0.01 \%$ ("A" point) in a mixture with the given physical conditions [21].

With the required coefficient of cyclic instability of the mean indicated pressure less than $5 \%$ and the misfire statistics not worse than, for example, $3 \%$, it is advisable to introduce the value of required ignition energy (RIE). Thus, the RIE is a portion of heat for the flame kernel formation with a probability of about $97 \%$ in a mixture of the given composition and other physical conditions ("C" point in Fig. 16). As is known, the RIE increases with mixture leaning.
The insufficient discharge energy and/or portion of heat introduced into the mixture, which is lower than the RIE but bigge than the MIE for the current operating conditions of the gas engine, can result in the misfire statistics, for example, about $50 \%$, and this situation is represented by the "B" point (Fig. 16).

\section{Development of an optimum method for the experimental study of the gas engine operation taking into account the phenomenon of cyclic instability of processes}

\section{1. Features of a practical study of the lean burn gas engine operation}

The cyclic instability of the work process, with regard to lean burn, is in a certain way affected by the cyclic instability of each of the engine processes prior to the flame kernel formation: the processes of the air-fuel supply system, ignition system and gas exchange system. In the practice of engine bench tests, an estimation of average values for a number of cycles (WP parameters, inlet and outlet temperatures and pressures, composition of exhaust gases, etc.) is commonly used. In the conditions of elevated CI, this approach for investigating the causes of the observed CIWP, for example, in lean burn gas engines, is limited. For example, the effect of the CI of the spark discharge as a means of supplying a portion of energy to the lean mixture makes it necessary to reconsider the approach and instruments of experimental research.

In the conditions of the engine test bench, a qualitative study of the share of influence of the instability of each of the processes prior to ignition on the cyclic instability of the combustion process requires a fundamentally new approach:

- all measured values have a random distribution and vary from cycle to cycle;

- processes can have a close interrelation - it is necessary to record all measured values of the cycle to the database, perform statistical processing and identify interrelations by the correlation method;

- the main reason for the problems and inconsistencies of the results is the imperfection of the experiment and equipment. For the timely detection of errors and problems, automation of the measuring complex providing the preliminary processed results is necessary.

In bench tests, it is customary to record the ID of at least 100 cycles for further analysis. However, in order to provide enough data for statistical processing and to determine the misfire statistics with an error not worse than $0.1 \%$, it is expedient to record data for 1,000 cycles in a constant operating mode.

So, at a crankshaft speed of $1,5001 / \mathrm{min}$, continuous shooting of 1,000 cycles on one displayed cylinder takes 80 seconds, i. e. less than one and a half minutes, which is acceptable for bench tests.

6. 2. Method of the experimental study of the effect of processes prior to ignition in the gas engine on lean burn

As an example, let us consider the problem of finding the RIE and the optimum aproach of its supply by spark discharge. A classical solution of this problem through a series of experiments in a "bomb" vessel filled with a compressed mixture with the observance of the constancy of initial con- 
ditions is known. However, the conditions of engine combustion differ from idealized ones.

Suppose, a number of quantities characterizing the processes are measured for each engine cycle in the course of an experiment on the engine test bench, for example:

- external mixture formation - air-fuel equivalence ratio $\lambda$;

- combustion - indicated effective pressure $P i$, ignition delay $T_{I G N}$;

- ignition - spark discharge energies at the spark plug electrodes $\left(E_{G L O W}, E_{A R C}\right)$.

If we concentrate on the distribution of one or each of the quantities separately for a cycle, we can only see the scatter of each of these quantities, without an answer to the question of the interrelation between them.

However, making the synchronous recording of all the measurements of interest for each cycle and saving them to a database, we are able to compare and trace the possible interrelations (Fig. 17).

In the simplest case, a graph of two measured values per 1,000 cycles recorded in a database synchronously to cycles, for example, the discharge energy and the mean indicated pressure in the form of points on the graph is plotted to estimate the statistics. One point represents one cycle, the set of points on the graph provide information on the density of the distribution of a random value.

In the presence of a regular component (Fig. 17), that can be recognise from density of poins, it is possible to determine the interrelation, to estimate the variation of the parameter of the initial conditions (discharge energy) and to estimate its influence on the combustion process by $P i$ and $T_{I G N}$. By the method of mathematical processing of measurement results, collected in the database, it is possible to determine the regular component. For example, for the given operating mode, a certain RIE as required energy of spark discharge will be experimentally determined.

However, in practice, in addition to the background of the regular component, there will be some random component. Random component is depends on the factors, perhaps not taken into account in this experiment and/or the method of data processing requires taking into account the more number of arguments. The experimental data can be interpret as function of two arguments - as example, energy of discharge in arc phase and energy of discharge in glow phase on the SP electrodes.

It is important that the constancy of other initial conditions during the experiment is also checked from the values recorded in the database: speed, inlet pressure, air-fuel ratio, etc.

The above is an example, but the technique is applicable for any values recorded synchronously for 1,000 cycles into the database. Implementation is possible through a measurement system with special solution by software and hardware parts.

Experimental studies of the combustion process in the gas engine up to the flammability limit are carried out in various operating modes, so-called "points". It is expedient to represent the obtained results in the form of characteristic maps (Fig. 3) as in [5]. The experimental study at each point (in each constant operating mode) includes:

- recording of sensor signals for a number of cycles of the investigated cylinder;

- processing of recorded signals in order to determine the parameters characterizing each individual cycle;

- collection of parameters of individual cycles for 1,000 cycles in the database at the "point" and statistical processing of the collected data in the given operating mode.

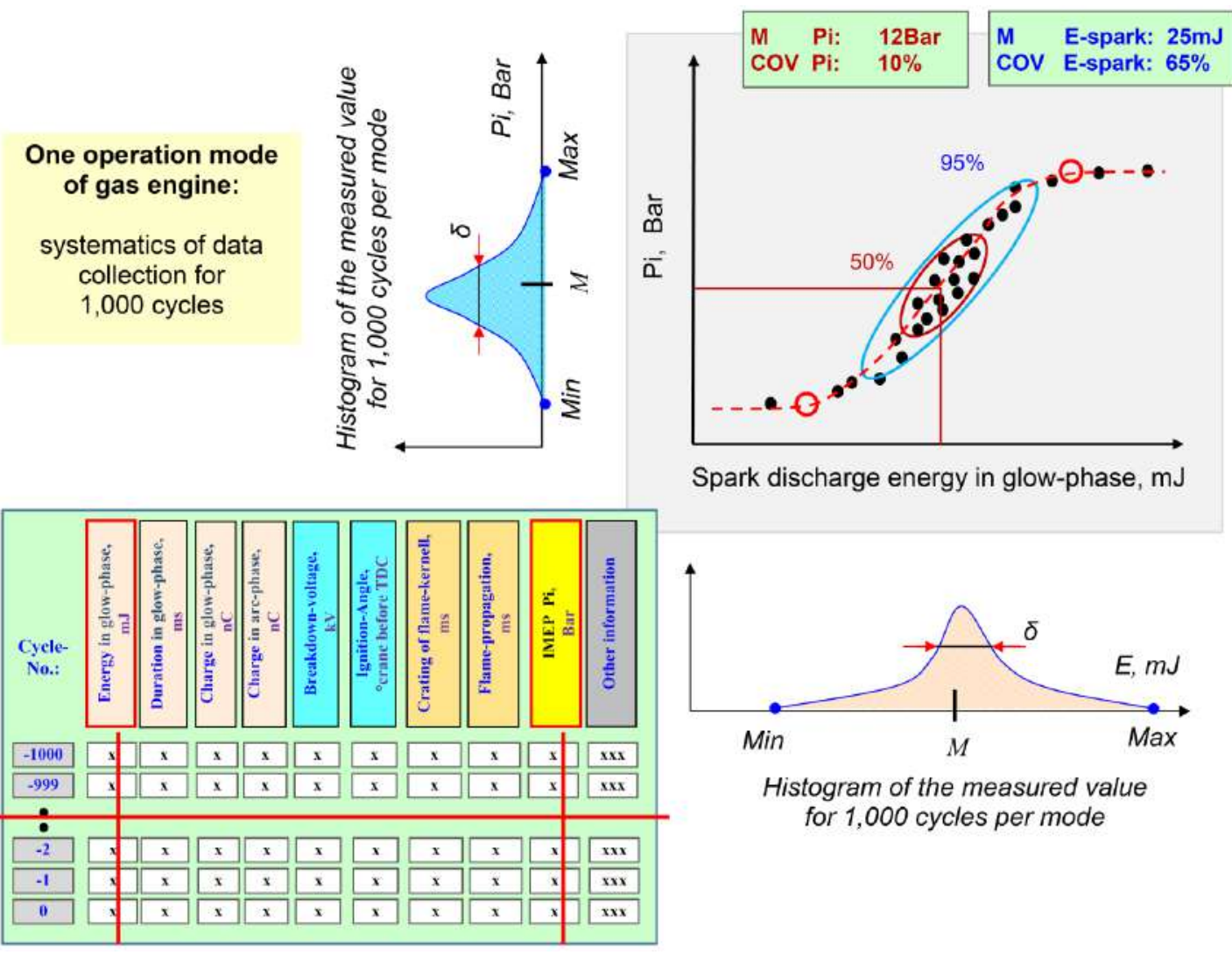

Fig. 17. Method of collecting experimental data for the last 1,000 cycles for statistical processing and identification of interrelations 
Based on the results of statistical processing, the operator evaluates the constancy of conditions in the operating mode and assesses the interrelation of the parameters (Fig. 17). The results of statistical processing supplement the characteristic maps as a document (for example, Excel) and all data are saved in a file, followed by the transition to the next point.

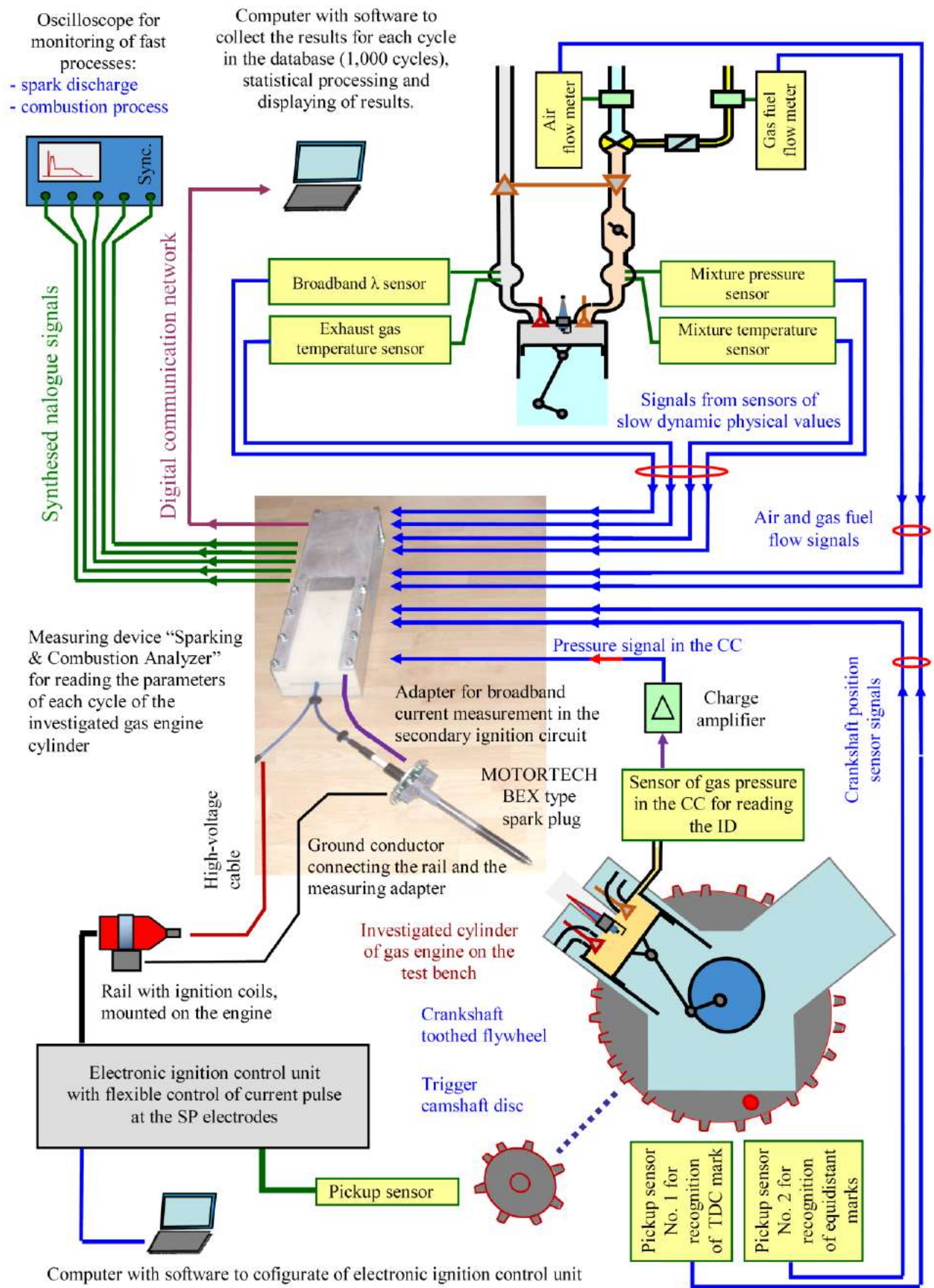

Fig. 18. Structure of the measurement system 
7. Functional requirements to the software and hardware parts of measurement system for studying the combustion process in gas engines

\section{1. Main objective of the measurement system}

Thus, for the implementation of the proposed method, the main objective of the fundamentally new measurement system with special solution by software and hardware parts is formed - to increase the reliability of the results of bench tests of gas engines in a constant operating mode by:

1) cycle-by-cycle measurement of spark discharge parameters with simultaneous recording and processing of indicator diagrams in real time, measurement of values in the air-fuel supply system and measurement of engine speed parameters per cycle;

2) synchronous recording of the measurement results for each cycle in the database for a number of cycles $(1,000)$ and statistical processing of the selected parameters to determine the distribution histogram of quantities, revealing the interrelation between the selected quantities and displaying the results in the form of graphs (Fig. 17);

3 ) automated processing of all results in accordance with items 1 and 2, taken in a constant operating mode (point) of the gas engine for timely identification of possible experimental errors.

\section{2. Structure of the measurement system}

To implement the tasks set, it is necessary to organize a data collection and processing system consisting of four main functional parts (Fig. 18), listed below.

Part A: installed sensors on the engine test bench and taking signals of physical processes in the gas engine in ignition, supply and gas exchange systems. The sensors are selected individually for the configuration of a particular test bench.

\section{Recording of voltage and current in time by discharge in secondary ignition circuit, automatic determination of spark discharge parameters at the SP electrodes}

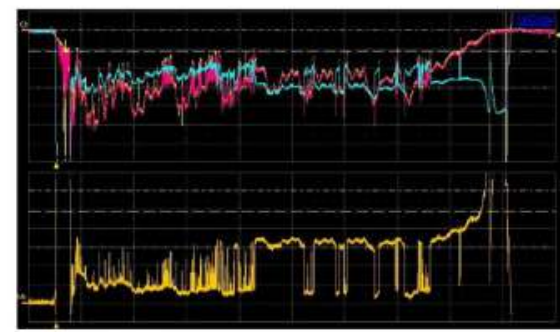
\. Parameters of cycle No. XY:

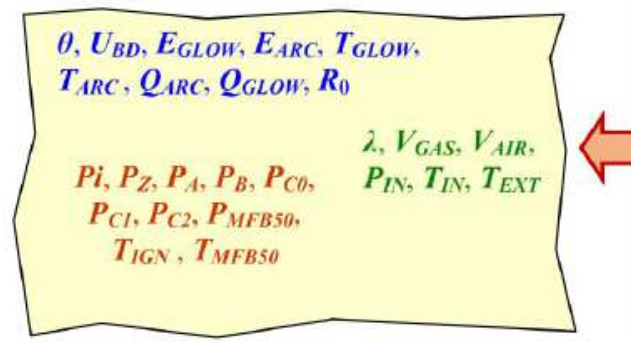

Measurement of parameters in the power and gas exchange system of the gas engine

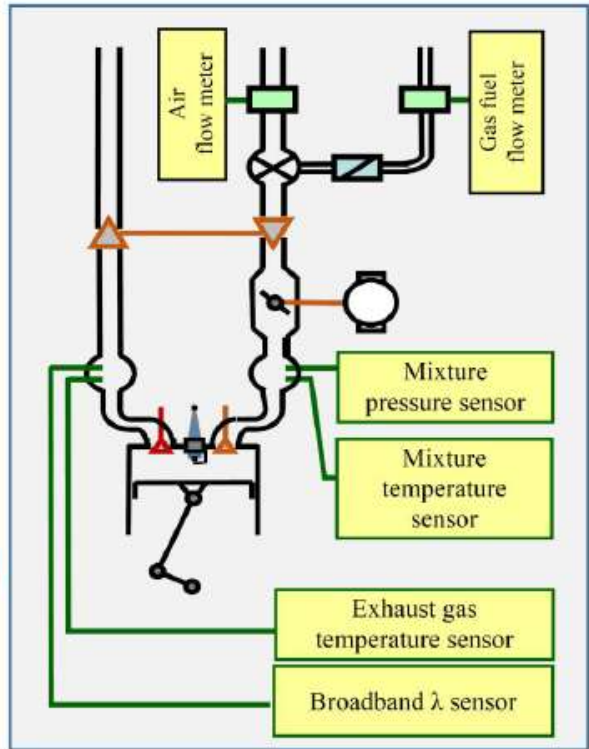

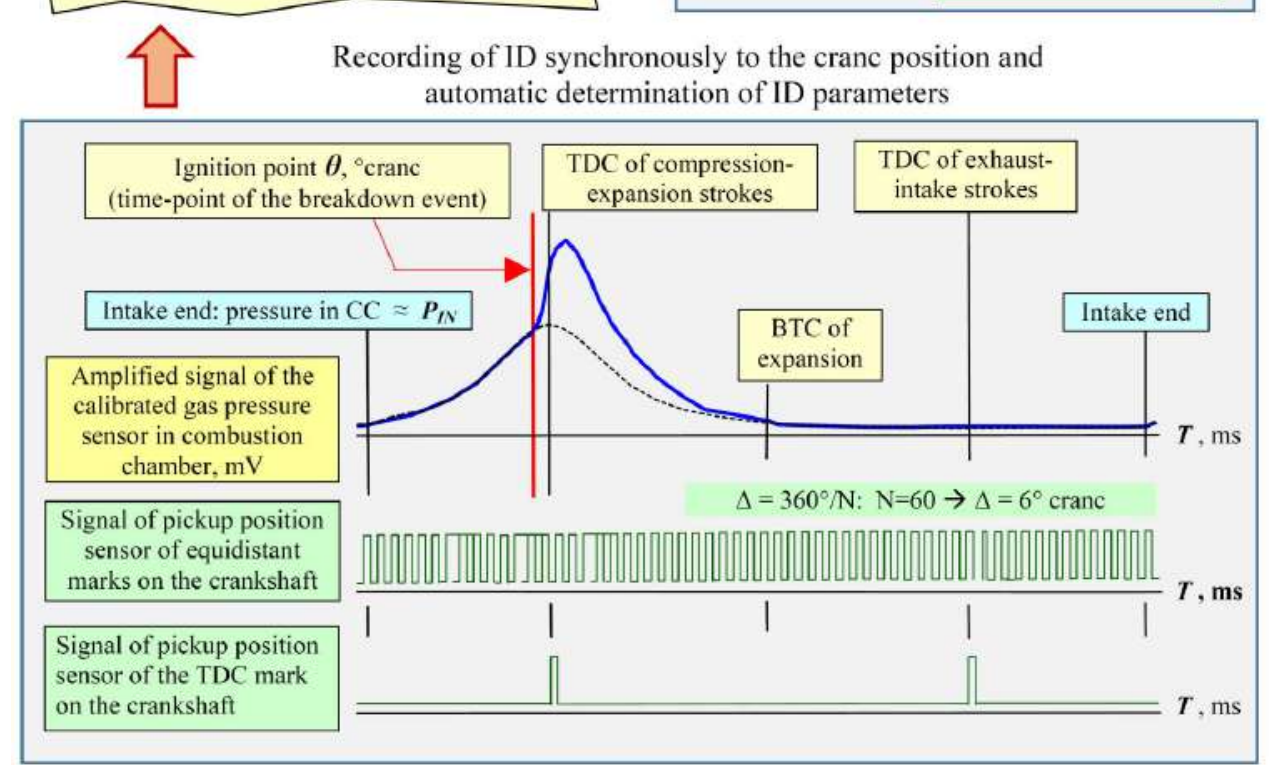

Fig. 19. Collection of experimental data characterizing a particular cycle of the investigated cylinder after automated primary processing of sensor signals in real time for timely transmission of message with cycle results to recording in the database 
Part B: the measuring device (for example, "Sparing/ Combustion Analyzer") for automated capture of the parameters of each cycle of the investigated cylinder by fast digital primary processing of sensor signals during the cycle (Fig. 19) and their timely transmission to PC by digital comunication network, for example, Ethernet or some passed logical protocoll by physical interface RS485 (Fig. 18).

An additional task of the measuring device is the synthesis of analog signals to display the processed graphs of fast processes in time through a digital oscilloscope. These include, for example, spark discharge values, grafic of ID and grafic of the specific power of the heat release by combustion process.

Part C: a computer with a specialized software for the described system to collect the results of individual cycles of the last 1,000 cycles into the database, statistical processing and displaying of the results to the operator (Fig. 17). The results of individual cycles come by serial digital comunication network in the form of data messages sent from the measuring device. The software of the measurement system allowes the operator to independently select several groups of values in the database for their statistical analysis in order to find the degree of interrelation between the values in selectet groops. The simplest and most visible method is the display of the results in the form of histograms and two-dimensional graphs with an array of points for the visual representation of the regular and random components. A quantitative measure of coincidence can be obtained by the correlation analysis.

Part D: a digital oscilloscope for displaying the processed fast processes of the previous cycle to the operator according to the signals, synthesized by the measuring device (Fig. 18).

Currently, the measurement system include measuring device "Sparking \& Combustion Analyzer", that implements the proposed methods, is under development as a startup at the ICE Department of the Kharkiv National Automobile and Highway University (Ukraine).

7. 3. Functional requirements to the primary processing of sensor signals for the engine cycle and to obtaining results per cycle

First of all, the following software and hardware functions are needed to implement in measuring device, that is a main part of measurement system of the laboratory gas engine bench (Fig. 18).

1) Fast software processing of the recorded indicator diagrams synchronously to crankshaft position, as well as the possibility of automated calibration and verification before the experiment through the first non-combustion cycle in the engine operation mode. The non-combustion cycle can be initiated due to artificial blocking of ignition by the operator. The results per cycle: $P_{i}, P_{Z}, P_{A}, P_{B}, P_{C 0}, P_{C 1}, P_{C 2}$, $P_{M F B 50}, T_{I G N}, T_{M F B 50}$.

2) Measurement of parameters of spark discharge at the spark plug electrodes, located in the combustion chamber of the displayed cylinder, by the rapid numerical processing of recorded signals of voltage and current of spark discharge, measured in outside of combustion chamber, due to taking into account resistance losses $R_{0}$ in the spark plug and spark plug connector [15]. Most types of spark plugs have a builtin resistor, the impedance of which can vary with the heating of the cylinder head. The results per cycle: $\theta, U_{B D}, E_{G L O W}$, $E_{A R C}, T_{G L O W}, T_{A R C}, Q_{A R C}, Q_{G L O W}, R_{0}$.

3) Processing of signals of gas and air flow meters, pressure and temperature sensors in the inlet and outlet mani- folds of the displayed cylinder, calculation of gas fuel consumption, air flow rate and mixture composition during the cycle. The results per cycle: $\lambda, V_{G A S}, V_{A I R}, P_{I N}, T_{I N}, T_{E X T}$.

4) Measurement of the crankshaft speed $n$ during the cycle.

5) Numerical processing of sensor signals for the calculation of special values according to the mathematical model, programmed to solve a narrow research problem. For example, the calculation of a portion of heat $E_{\text {heat }}$, transferred to the gas medium by means of spark discharge. The calculation can be performed according to the experimental dependences, described in [9]. The implementation is possible through the software for processing the recorded voltage and current signals of the secondary ignition circuit:

- obtaining the spark discharge power $P_{S P}(t)$;

- obtaining data on the discharge phase (arc or glow) according to the current amplitude $I_{I C}(t)$;

- determination of the heat transfer power $P_{\text {heat }}(t)$ according to the experimental dependences [9] $\left(P_{\text {heat }}(t)=\mathrm{F}\left(P_{S P}(t)\right)\right)$ taking into account the data on the discharge phase;

- calculation of the integral of the power of heat transfer $\left(E_{\text {heat }}=\int P_{\text {heat }}(t)^{*} d t\right)$ into the gas medium surrounding the spark plug electrodes.

Also, an experimental verification of the chosen mathematical model as a theoretical background can be implemented. An example, according to [20], can be the calculation of the flame kernel formation time $T_{I G N-M a t h}$ depending on the spark discharge power $P_{S P}(t)$. Comparison of the experimental $T_{I G N}$ and calculated results $T_{I G N-M a t h}$ for a number of cycles recorded in the database allows experimental verification of the mathematical model [20] on a lean limit gas engine.

6) By serial digital comunication network (as example, Ethernet or some passed logical protocoll by physical interface RS485), a transmission of the above-mentioned final values for each cycle include nomber of cycle as a digital message to the PC. The transmition of results for cycle should be finished in time before next cycle. This is neccery for timely collecting of results in the database for the last 1,000 cycles, processing the statistics of the results for the last 1,000 cycles and displaying in a graphical form for operator via PC software.

7) Output of analog signals to the oscilloscope for visual displaying of the flow of fast processes in each cycle, there are the spark discharge and combustion processes:

a) sygnal of the current impulse $I_{I C}(t)$ of the SP electrodes in the CC;

b) sygnal of the voltage impulse $U_{S P}(t)$ at the SP electrodes in the $\mathrm{CC}$, obtained by mathematical processing of voltage and current signals;

c) sygnal of the electric discharge power impulse $P_{S P}(t)$ at the SP electrodes in the $\mathrm{CC}$;

d) sygnal of the work process $P(\Theta)$ - detailed ID of the cycle, recorded synchronously with the crankshaft angle (CSA);

e) sygnal of the compression-expansion line $P_{C E}(\Theta)$ - the ID of the non-combustion cycle in the mode, taken synchronously with the CSA;

f) sygnal of the pressure difference $\Delta P(\Theta)$ synchronously with the CSA - the operating pressure and the compression-expansion line. It serves for a rough visualization of the heat release process and finding the "separation point" as a conditional criterion of the beginning of heat release, i. e., the end of the flame kernel formation and the beginning of the flame front propagation in the combustion chamber. On the oscillogram, the ignition delay - the time between the spark discharge start and the "separation point" will be noticeable; 
g) sygnal of the variation magnitude of the crankshaft speed $\Delta n(\Theta)$ (difference between current value of speed and average value during dte cycle), recorded synchronously with the CSA;

h) sygnal of the transfered heat as power $P_{\text {heat }}(t)$ from SP in to the gas medium by means of spark discharge, calcuated according to programmed heat transfer function dependens on the phase of sparc discharge - arc or glow. This function should be realized as an additional program function of the device;

i) sygnal of the specific heat release $P_{\text {combustion }}(\Theta)$ as specific power of combustion process synchronously with the CSA, calculated according to the mathematical model and realized as an additional program function of the device.

\section{Discussion of the method of experimental study of the combustion process in the lean burn gas engine on the engine test bench}

The reason for the CICP can be the instability of the initial conditions before ignition of mixture. In practice, the work process parameters, taken for a number of cycles in the mode, are a physical quantity with a random distribution according to a certain law. However, all processes are interrelated. The initial conditions before the primary flame kernel formation mixture composition and stratification degree, charging and motion profile of the mixture in the combustion chamber, energy supply through the ignition system - can vary from cycle to cycle for a number of reasons. To increase the reliability of results, a quantitative evaluation of the physical quantities characterizing the processes, both before ignition and the work process itself, with their statistical processing over many engine cycles in the operating mode of interest is needed.

By combining the means of measuring the parameters before mixture ignition, spark discharge and WP ID processing for each individual cycle into a single automated synchronous data recording system when collecting data for a variety of cycles, their maximum informativeness is achieved. The informativeness of the collected data allows carrying out statistical processing in order to reveal the degree of interrelation. Additional automation of data processing makes it possible to reduce the time of detection of experimental errors.

The method is necessary in the experimental study of interrelations in conditions of increased cyclic instability, manifested when approaching the lean limit in lean burn gas engines

It is worthwhile to consider the existing means of studying the operation of both gas and other piston engines.

Existing engine testers monitor many processes. However, they solve the problem of quality (for fault diagnosis), but not quantity evaluation of the parameters of interest, and therefore cannot be used.

There is a universal equipment for recording and processing indicator diagrams (for example AVL, Kistler, IAV, IMES, Daytran manufacturers, etc.), used both for diesel and other piston engines. The main objective of this equipment is to study combustion processes as a result in accordance with the generally accepted bench test methods. It is a professional measuring equipment characterized by a relatively high cost, inability to independently supplement and change the processing of the exposure of sensor signals in a wide range. Specific supplements are possible only within the manufacturer services.

For the benches on the basis of serial engines, there is equipment for measuring certain physical processes before ignition outside the combustion chamber. For example, air and gas fuel flowmeters, recorders of sensor signals of mixture pressure and temperature at different points of the intake manifold.

On the spark part, it is possible to use high-voltage probes (for example, North Star PVM-5), a shunt, a low-voltage probe and a broadband digital oscilloscope with the function of mathematical signal processing [19].

However, in connection with the described problems of cyclic instability of both pre-ignition processes and the combustion process itself, it is necessary to implement the new research method described above for the investigation and further optimization of the lean burn gas engine. There are the following implementation options:

a) to combine purchased equipment into a whole mesurement system with the involvement of manufacturers' services. For example, it is necessary to synchronously collect measurement results from each instrument for each cycle in a single database, which should be supported by digital data exchange interfaces;

b) to develop own measurement system with special solution by software and hardware parts, designed to solve the described range of research tasks. The implementation can be based on purchased sensors, high voltage measurement technique, modern electronic components, programable logick design, development of own embeded and PC processing software as an open source.

At the moment there is no equipment that implements the proposed method in full. At least, there is no equipment that integrates the functions of analyzing the spark discharge signals and combustion from ID of WP, measuring their characteristics for one cycle in real time. Spark discharge and combustion are relatively fast processes and a combination of both functions requires a special hardware-software solution. Thus, the implementation of the method requires the development of new measurement equipment with a significant amount of engineering work. The results of experiments obtained by means of the described measuremen system will give a more detailed picture of the processes occurring in spark-ignited gas engines with the chosen design solution. This will significantly reduce the risk of experimental error, increase the information content and reliability of results.

\section{Conclusions}

1. The cyclic instability of combustion processes in lean burn gas engines can be caused by the cyclic instability of pre-ignition processes: mixture formation, charging, ignition. All processes are interrelated. Process parameters should be considered as a random variable with a certain distribution law. The instability of the primary flame kernel formation process is most affected by energy supply by means of spark discharge, constancy of mixture composition and stratification degree in the combustion chamber at the time of ignition. The cyclic instability of the flame front propagation process is most affected by the instability of the charge velocity profile, constancy of mixture composition and stratification degree in the combustion chamber.

2. The electric discharge at the spark plug electrodes is a technical means of transferring energy to the local area of the mixture. Spark discharge with a long glow phase and the process of heat transfer into the gas medium have cyclic instability, which is explained by the spark discharge physics 
and the complex interrelations with the conditions of the gas medium surrounding the electrodes. The probability of the primary flame kernel formation is proportional to the portion of heat transferred to the mixture and closeness of mixture composition to stoichiometric. For certain conditions of the mixture at the moment of ignition, there is the necessary energy, where the probability of the primary flame kernel formation is acceptable for the stable operation of engines. The arc phase of the spark discharge increases the erosion of the spark plug electrodes. Under certain conditions, spontaneous transitions between the arc and glow discharge phases are possible. There is the possibility to optimize the discharge current shape.
3. Taking into account the cyclic instability of the processes, the method for simultaneous collection of the preliminary processed results of cyclic measurements into the database for a set (for example 1,000) of cycles for the subsequent statistical data processing implemented by the program on a PC is proposed.

4. The basic functional requirements to the fast primary numerical processing of sensor signals during each individual cycle, implemented by the measurement system with the transfer of final cycle results to the PC, are generated. For the purpose of universality, it is possible to add new software functions and/or connect compatible hardware modules to solve a specific research task on the engine test bench of gas engines.

\section{References}

1. Avtomobilni dvyhuny: pidruchnyk / Abramchuk F. I., Hutarevych Yu. F., Dolhanov K. Ye., Tymchenko I. I. Kyiv: Aristei, 2007. 476 p.

2. Abschlussbericht SFB 224. URL: http://www.sfb224.rwth-aachen.de/bericht.htm

3. Herdin G., Herdin R. Grundlagen Gasmotoren. PGES GmbH, Germany, 2012. 54 p. URL: http://www.prof-ges.com/lectures/ Gasmotoren_Script_20120418.pdf

4. Buschbek M. Laseroptische Analyse der zyklischen Schwankungen in einem Transparentmotor: dissertation. Technische Universität Darmstadt, 2013. 131 p. URL: http://tuprints.ulb.tu-darmstadt.de/3379/1/Diss_Buschbeck_online.pdf

5. Puhl M. Corona and Laser Ignition in Internal Combustion Engines, A comparison to conventional spark plug ignition. VDM Verlag Dr. Müller, Saarbrücken, 2011. 124 p. URL: https://www.morebooks.shop/store/de/book/corona-and-laser-ignition-ininternal-combustion-engines/isbn/978-3-639-32311-5

6. Rager J. Funkenerosion an Zündkerzenelektroden. Naturwissenschaftlich-Technischen Fakultät III Chemie, Pharmazie, Biound Werkstoffwissenschaften der Universität des Saarlandes, 2006. 168 p. URL: https://www.deutsche-digitale-bibliothek.de/ item/52TUM6PRG46OISG5CZSWHH7QIO5GUAZW

7. Küchler A. Hochspannungstechnik. Springer-Verlag Berlin Heidelberg, 1996. 398 p. doi: https://doi.org/10.1007/978-3-66221999-7

8. Jeanvoine N., Jonsson R., Muecklich F. Investigation of the arc and glow phase fractions of ignition discharges in air and nitrogen for Ag, Pt, Cu and Ni electrodes // 28th ICPIG ( July 2007). Prague, Czech Republic, 2007. P. 284-287. URL: http://icpig2007. ipp.cas.cz/files/download/cd-cko/ICPIG2007/pdf/1P03-04.pdf

9. Saggau B. Kalorimetrie der drei Entladungsformen des elektrischen Zündfunkens // Archiv für Elektrotechnik. 1981. Vol. 64, Issue 3-4. P. 229-235. doi: https://doi.org/10.1007/bf01574305

10. Bane S. P. M. Spark ignition - experimental and numerical investigation with application to aviation safety. California Institute of Technology, Pasadena, 2010. 284 p. URL: https://thesis.library.caltech.edu/5868/1/thesis_SBane.pdf

11. Schvydkyi D. Modern ignition systems for gas engines // Vestnik Har'kovskogo nacional'nogo avtomobil'no-dorozhnogo universiteta. 2014. Issue 64. P. 41-49. URL: http://dspace.khadi.kharkov.ua/dspace/handle/123456789/950

12. Modelling of modulated capacity discharge ignition systems / Meyer G., Stadlbauer K., Gschirr A., Lindner-Silwester T., Puttinger St. // 8. Dessauer Gasmotoren-Konferenz. 2013. P. 253-265.

13. Wirkungsgradpotenziale bei der ungespülten Vorkammer / Herdin G., Herdin R., Grewe F., Warkentin P. // 14. Tagung "Der Arbeitsprozess des Verbrennungsmotors”. Institut für Verbrennungskraftmaschinen und Thermodynamik, Technische Universität Graz., Austria, 2013. P. 110-126.

14. Flow and Combustion in Reciprocating Engines / C. Arcoumanis, T. Kamimoto (Eds.) // Springer-Verlag Heidelberg, Germany, 2009. 420 p. doi: https://doi.org/10.1007/978-3-540-68901-0

15. Svetcov V., Holodkov I. Fizicheskaya elektronika i elektronnye pribory: ucheb. pos. Ivanovo, 2008. 494 p.

16. Fitzner A. O., Hager J. R. RFI-suppressing ignition system for an internal combustion engine: Pat. No. US4186712A. URL: https:// patents.google.com/patent/US4186712A/en

17. Tai T.-T. Ignition cable means for eliminating inerference: Pat. No. US5603306A. URL: https://patents.google.com/patent/ US5603306

18. Abramchuk F., Kabanov A., Shvydkiy D. Analiz effektivnosti odnoiskrovoy i mnogoiskrovoy sistem zazhiganiya gazovyh dvigateley // Avtomobil'niy transport. 2014. Issue 34. P. 28-31.

19. Abramchuk F., Kabanov A., Shvydkiy D. Metodika opredeleniya elektricheskih velichin sistemy iskrovogo zazhiganiya DVS // Avtomobil'niy transport. 2013. Issue 33. P. 67-70.

20. Francev S. Uluchshenie pokazateley gazovyh DVS za schet racional'nogo vybora parametrov iskrovogo razryada sistemy zazhiganiya: diss. ... kand. tekhn. nauk. Volgograd, 2009. 127 p.

21. Teoriya razvitiya i prekrashcheniya goreniya: metod. ukaz. / Tarahno E. V., Zhernoklev K. V., Tregubov D. G., Kovregin V. V. Kharkiv, 2013. $162 \mathrm{p}$. 